FedUni ResearchOnline

http://researchonline.federation.edu.au

This is the peer-reviewed version of the following article:

Guinea, A., Playà, E., Rivero, L., Ledo, J.J., Queralt, P. (2012) The electrical properties of calcium sulfate rocks from decametric to micrometric scale.

Journal of Applied Geophysics, 85, 80-91.

Which has been published in final form at:

http://doi.org/10.1016/j.jappgeo.2012.07.003

Copyright (C) 2012 Elsevier B.V. All rights reserved. 


\title{
THE ELECTRICAL PROPERTIES OF CALCIUM SULPHATE ROCKS FROM DECAMETRIC TO MICROMETRIC SCALE
}

(1)

\author{
Ander Guinea $^{1 *}$, Elisabet Playà ${ }^{1}$, Lluís Rivero ${ }^{1}$, Juan José Ledo ${ }^{2}$, Pilar Queralt ${ }^{2}$ \\ ${ }^{l}$ Departament de Geoquímica, Petrologia i Prospecció Geològica. Facultat de Geologia, Universitat de Barcelona (UB). \\ Martí i Franquès s/n, 08028 Barcelona, Spain. \\ ${ }^{2}$ Departament de Geodinàmica i Geofísica. Facultat de Geologia, Universitat de Barcelona (UB). Martí i Franquès s/n, \\ 08028 Barcelona, Spain. \\ E-mails: anderguinea@ub.edu; eplaya@ub.edu; lrivero@ub.edu; jledo@ub.edu; pilar.queralt@ub.edu \\ *Corresponding author: Phone number: +349340311 65. Fax number: +34 934021417
}

\section{ABSTRACT}

Sulphate rocks have a sedimentary evaporitic origin and are present in many deposits worldwide. Among them, gypsum (dihydrated calcium sulphate) is the most common and is exploited for industrial purposes. Anhydrite (calcium sulphate) is frequently found in gypsum quarries and in non-outcropping sulphates. The greater hardness of anhydrite compared to gypsum causes a problem for gypsum extraction; quarry fronts have to be halted as soon as anhydrite is found. In this work the electrical properties of calcium sulphates have been studied by means of geoelectrical methods.

and their lithological composition has been established with the lutitic matrix being the main controlling factor when it is well connected. When the matrix is under the percolation threshold the sulphate phases are dominant, and the electrical response of the rocks depends on the percentage of each phase. When the rock is matrix dominant, the electrical resistivity trend fits with the Hashin- 
26 Shtrikman lower bound for multiphase systems (considering gypsum, anhydrite and matrix as the 27 components). On the other hand, when the rock is calcium sulphate dominant the trend shows the one 28 of the Hashin-Shtrikman upper bound. The reference electrical resistivity value of pure anhydrite 29 rocks has been defined as $10^{4} \Omega . \mathrm{m}$ and geoelectrical classification for calcium sulphate rocks has been 30 elaborated. With this classification it is possible to differentiate between calcium sulphate rocks with 31 different composition from their electrical resistivity value. This classification has been checked with 32 field examples and calculating the theoretical resistivity value of thin section photographs with the 33 program ELECFEM2D. The electrical behavior of calcium sulphate rocks is a good reference for other 34 type of rocks with electrically differentiated components, and similar methods can be used to define 35 their geoelectrical responses. 


\section{INTRODUCTION}

Evaporites are sedimentary rocks originated from evaporation of salty water. Sulphates are one of the principal groups of evaporitic rocks and the principal sulphate minerals are: gypsum $\left(\mathrm{CaSO}_{4} \cdot 2 \mathrm{H}_{2} \mathrm{O}\right)$, anhydrite $\left(\mathrm{CaSO}_{4}\right)$, glauberite $\left(\mathrm{Na}_{2} \mathrm{Ca}\left(\mathrm{SO}_{4}\right)_{2}\right)$ and thenardite $\left(\mathrm{Na}_{2} \mathrm{SO}_{4}\right)$ (Warren, 2006). Texturally, sulphate rocks are mainly crystalline; but may appear with clastic textures when they are reworked. They retain only a reduced primary porosity $(<1 \%)$, display a restricted mineralogical (and geochemical) composition and can appear combined with a lutitic matrix (mainly composed of clay and microcrystalline carbonates). The texture of rocks are affected extensively by diagenetic processes which can become microcrystalline. Gypsum tends to transform to anhydrite when buried as a result of dehydration, and the opposite process also takes place when anhydrite is affected by weathering and superficial waters (Holliday, 1970).

Gypsum deposits are exploited for industrial purposes. It is mainly used in construction as drywall and as an ingredient for plaster, but it is also used in other industries (Bustillo et al., 2001). Gypsum quarries occur worldwide, with the USA and Iran as the largest producers. One of the most important problems found while quarrying gypsum is the presence of anhydrite. By comparison with gypsum, anhydrite is harder and denser. The drilling machines can be damaged by anhydrite bodies. Hence, the exploitation must be stopped immediately. Anhydrite is also used by industry for different purposes, but because of the exploitation difficulties it is mainly obtained by dehydration of previously extracted gypsum. Anhydrite (from gypsum dehydration) is commonly found deeply buried (up to 1000 m; Shearman, 1985; Warren, 2006). It rarely crops out because it tends to hydrate and transform into gypsum. resistivity tomography (ERT) is a geophysical technique which can be used to obtain an image of the electrical resistivity distribution of the subsurface. For this purpose an array of metal electrodes are planted in the soil and the difference of electrical potential is measured between pairs of them while a direct current (DC) is passed between two others. The arrangement of these 4 electrodes depends on 
the electrical array that has been selected and the measurement is repeated along the string of electrodes at different spacings and positions. The apparent resistivity values obtained are inverted into resistivity values as a function of depth and position using inversion software (RES2DINV, Geotomo Software, ver. 3.5). This method is a rapid, non invasive and relatively low-cost.

Gypsum deposits have been successfully identified with ERT profiles (Lugo et al., 2008; Guinea et al., 2009; Guinea et al., 2010a). Guinea et al. (2010b) produced a geoelectrical classification of gypsum rocks establishing a direct relation between their electrical resistivity value and the percentage of lutitic matrix (Table 1). In that study the anhydrite phase was not considered, but this mineral very often appears in gypsum rocks. The scientific literature shows anhydrite to have a large range of resistivities from <100 to $10^{10}$ S.m (Table 2; Jakosky, 1950; Parkhomenko, 1967; Rider, 1986; Robison and Çoruh, 1988; Choteau et al., 1997; Asfahani and Mohammad, 2002; Lugo et al., 2008). The variation in the electrical resistivity value of anhydrite in these publications is related to the presence of gypsum, but the influence of the lutitic matrix is not mentioned.

The aim of this study is to measure the electrical resistivity of pure anhydrite at zero frequency and to establish the effect of compositional variations in the gypsum-anhydrite-lutite rock system. This problem will be studied from three different angles, namely numerical modeling, laboratory measurements and field data. The information thus obtained should help to interpret geoelectrical data in future surveys on sulphate rocks.

\section{FIELD DATA}

\subsection{Geological setting}

During the Lutetian (Middle Eocene) a large marine evaporitic sequence was deposited in the South Pyrenean Foredeep (Rosell and Pueyo, 1997). In the La Garrotxa area (eastern Pyrenees) secondary gypsum (as product of the hydration of anhydrite) crops out extensively and anhydrite has 
been found in borehole logs with other evaporitic rocks such as halite (Carrillo, 2009). Close to the village of Beuda (Girona, Spain) there is a quarry in which gypsum has been exploited since at least the 1930s. There are many sculptures made of alabaster (pure secondary microcrystalline gypsum) from the Middle Ages for which geochemical analysis has demonstrated that they were extracted from the Beuda gypsum unit (Inglés et al., 2009).

Nowadays the quarry has been largely developed and anhydrite crops out in many places and where the exploitation has consequently been stopped. The gypsum of the Beuda unit was produced by hydration of anhydrite and therefore there are still some anhydrite relict bodies embedded in the gypsum. In the walls of the quarry it is possible to observe boundaries between gypsum and anhydrite usually displaying a quite pure anhydrite core and a transition to pure gypsum (Figure 1A). The purity of the calcium sulphate varies from higher than $90 \%$ to close to $75 \%$ in certain layers (Figure 1B). The changes in the purity of both gypsum and anhydrite rocks and the complex geometrical relations between them make these deposits very heterogeneous. In some cases matrix bearing gypsum appears in contact with pure anhydrite and in other cases the anhydrite does not appear as a body but as fragments embedded in gypsum and filled with gypsum veins (Figure 1C). In other places anhydrite appears massive with little gypsum within (Figure 1D). Three ERT profiles (figure 2, A, B, and C) have been performed in the Beuda gypsum quarry. Profile D (Figure 2D) has been performed in the same formation of the Beuda quarry, close to the village of Serinyà. In the area studied there are sulphate layers under a soil. In the nearby outcrops pure secondary gypsum appears, but at depth, the sulphates probably transform into anhydrite as it has been observed in the region (Carrillo, 2009).

Marine evaporitic deposition took place during the upper Eocene on the Catalan margin of the Ebro basin (Ayora et al., 1994). The Odena gypsum unit was extensively exploited during the $20^{\text {th }}$ century and there are many abandoned quarries in the region. Profile E has been carried out in an abandoned quarry near to the village of Odena where anhydrite crops out (Figure 2E).

In the Montes de Torrero area (Zaragoza, Spain) there is a Miocene evaporitic formation hundreds of meters thick. The area has been studied by means of boreholes in which gypsum, 
116 anhydrite, glauberite and halite were found among other minerals. This formation has a large quantity

117 of matrix in every layer (Ortí, 2000; Salvany, 2009). The outcropping materials are mainly gypsum,

118 which formed from the hydration of anhydrite or glauberite (Figure 1E), and more than 50\% matrix 119 (composed of clay and marl). An ERT survey has been performed where borehole B4 was drilled 120 (Figure 2F). The $\log$ of the borehole shows gypsum to a depth of $35 \mathrm{~m}$, then glauberite to a depth of 69 $121 \mathrm{~m}$ followed by anhydrite to $80 \mathrm{~m}$ with some interbedded layers of halite or glauberite (Salvany, 2009).

122 The whole log shows significant fractions of matrix at all depths as such as at the surface.

A total of six ERT profiles have been carried out at anhydrite rock deposit areas in the South Pyrenean Foredeep and Ebro Basin (North East of Spain; Figure 3). The examples are presented below starting with those performed in quarries (Figure 3; A, B, C and D) and afterwards in areas with no evaporites that crop out (Figure 3; E and F). All the profiles performed in quarries show a high fraction of sulphates and therefore relatively high electrical resistivity values.

A Syscal Pro Switch ERT system with 48 electrodes and an external power supply has been used to carry out the data acquisition. The electrode spacing for the measurements in quarries was 0.5 ,

1311.5 or $2 \mathrm{~m}$ depending on the local conditions. In the profiles performed where no evaporates crop out,

132 the electrode spacing was $10 \mathrm{~m}$ to increase the depth of investigation because anhydrite deposits tend 133 to appear below other formations (because at shallow depth they transform into gypsum). The used 134 electrodes for the data acquisition were made of stainless steel and they were nailed in the terrain by means of hammers. There are many possible array configurations in geophysical prospection (Ma et al., 1997; Furman et al., 2003; Szalai and Szarka, 2008) which may be applied to anhydrite rocks. The

137 Wenner-Schlumberger and Dipole-Dipole arrays have been selected depending of the structure under 138 study, and the Dipole-Dipole has been used were lateral electrical resistivity changes are important.

139 The apparent resistivity data of performed ERT profiles has been inverted with the RES2DINV 140 program; that is available from 1995 (Loke and Barker, 1996). The inversion process has been carried 141 out with 5 iterations for each profile. With this number of iterations the data converges in all cases 
achieving an acceptable RMS error. Additional iterations do not vary the RMS error significantly but

143 increase the electrical resistivity value in the low sensitivity areas (i.e., the pure sulphate rocks). As

144 explained later in Section 2.3, the resistivity range calculated (with 5 iterations) in pure anhydrite

145 bodies at depth is alike to the apparent resistivity measured in shallow pure anhydrite rocks. their composition. The samples have been powdered and $0.5 \mathrm{~g}$ from each one has been dissolved in

$148250 \mathrm{ml}$ of distilled water in accordance with the solubility of calcium sulphate in water. The solutions

149 were shaken for 24 hours at $25 \mathrm{C}^{\mathrm{o}}$ and then filtered. The residue left after filtering correspond to the 150 non-soluble phases, which are made up of the lutitic matrix (including carbonates, quartz and other 151 minor accompanying minerals). The residue was weighted in order to estimate the fraction of the in 152 sulphate phases.

\subsection{Results and discussion}

In the Beuda quarry some different areas have been studied. The profiles A and B have been performed upon areas in which massive anhydrite was found and afterwards was buried under quarry waste materials. The profiles were spread above the infilling. The result of the inversion for Profile A (Figure 3A) display an upper part with relatively low electrical resistivity values (between 10 and 200 $\Omega . m)$, which corresponds to the quarry waste. Underlying these materials there is a homogeneous body with high resistivity value (up to $10^{4} \Omega . \mathrm{m}$ ), which has been interpreted as pure anhydrite (Lugo et al.,

160 2008). In the case of Profile B, which was performed perpendicularly to Profile A, the inverted resistivity section (Figure 3B) displays a lateral electrical resistivity variation below the quarry waste

162 layer. A well was drilled in the middle of profile B and high hardness was found at 6 meter depth, but 163 no core was recovered. This hardness has been interpreted as anhydrite rock with certain quantity of 164 matrix.

The profile $\mathrm{C}$ has been measured in other location where anhydrite had also stopped the exploitation of the quarry. The electrodes were inserted almost directly into the sulphate rocks and 
167 both anhydrite and gypsum appeared in the ground surface. In the inverted resistivity section (Figure

168 3C) there is displayed a lateral variation of electrical resistivity ranging from $10^{3}$ to $10^{4} \Omega$.m. The 169 larger resistivity values are limited with the outcropping of massive anhydrite, while the lower ones 170 are related to the presence of gypsum, and the intermediate values correspond to the transition between 171 the two pure phases.

Profile D has been performed in an abandoned quarry near to the village of Odena where anhydrite crops out. The inverted section (Figure 3D) shows electrical resistivities ranging from $10^{3}$ to

$17410^{4} \Omega . \mathrm{m}$, similarly to the observations in the Beuda quarry. In the areas in which the value is larger, 175 massive anhydrite is observed. Lower electrical resistivity than 500 S.m are related to lutitic 176 sedimentary layers. profile (Figure 3E) displays a shallow deposit with a low electrical resistivity value (50 $\Omega . \mathrm{m})$ which corresponds to the underlying materials. Below this layer there is a high resistivity body ranging from

1801000 to more than $5000 \Omega . \mathrm{m}$ and with a more conductive structure in the central part (between 100 181 and $200 \Omega . \mathrm{m})$. This structure represents a fault present in the area, and identified on the surface by 182 geological evidence (Carrillo, 2009).

The profile F performed in Montes de Torrero area has been modified from Guinea et al.

184 (2010b). In the inverted image (Figure 3F) the whole deposit shows a general trend of 30-50 $\Omega . m$ with some bodies slightly more resistive (up to $300 \Omega . \mathrm{m}$ at the most resistive points). Those bodies would represent a higher grade of the deposit (up to $60 \%$ in sulphates) in these zones, this grade changes are related to primary depositional processes and they are very common in these materials (Guinea et al.,

188 2010a). In any case it is not possible to differentiate between anhydrite and gypsum layers because the 189 electrical behavior of the deposit is dominated by the abundant matrix. 
192 for pure anhydrite rocks because in some profiles in which some of the shallowest points have been

193 measured almost directly above massive anhydrite rocks, show an apparent resistivity value larger 194 than $5000 \Omega$.m. In these cases the apparent and the inverted resistivities are similar but a slightly lower 195 for the apparent resistivity because the electrodes are inserted into a thin clay layer. When these rocks 196 are mixed with gypsum forming pure sulphate rocks with both phases, which are the most common in 197 the quarries, they display an intermediate value of resistivity ranging from 1500 to $5000 \Omega . \mathrm{m}$ 198 depending on the quantity of each phase. As the distribution of the anhydrite in the gypsum deposits is 199 very heterogeneous due to the rehydration processes, the tomography lines show heterogeneous bodies 200 with different electrical resistivity values and transitional zones. Values close to $1000 \Omega . \mathrm{m}$ are related 201 to the purest gypsum rocks or to pure anhydrite with a significant quantity of matrix rocks. When the matrix has a large volume fraction, it is not possible to differentiate is gypsum from anhydrite with 203 ERT. In these cases, the rocks will display a resistivity below $100 \Omega$.m, which is significantly lower 204 than the resistivity of sulphate-rich deposits. The low electrical resistivity of sulphate deposits with 205 large matrix volume fraction was studied further by Guinea et al. (2010b) for the case of gypsum rocks 206 (without anhydrite).

\section{LABORATORY MEASUREMENTS}

\subsection{Methods}

Many authors have measured the electrical conductivity of geological materials (Keller, 1966;

211 Lockner and Byerlee, 1985; Guéguen and Palciauskas, 1994; Glover et al. 1996; Giao et al., 2003; 212 Rusell and Barker, 2010; among others). Guinea et al (2010b) made eleven gypsum-clay pills in 213 different proportions with a range from 0 to $100 \%$ of $\mathrm{CaSO}_{4} \cdot \mathrm{H}_{2} \mathrm{O}$ at intervals of $10 \%$ in composition 214 and measured their electrical conductivity. Three sets of eleven anhydrite-lutite pills and three sets of 215 gypsum-lutite pills have been made using the same methodology, parameters and resources. The 216 compositional error of the pills is below $1 \%$, because the weight corresponding to the volume of each 
217 fraction has been measured with a precision scale (Sarorius B3100S) with a resolution of $0.01 \mathrm{~g}$ (the 218 pills have a total weight of $13.5 \mathrm{~g}$ ). The pills have a cylindrical shape with a radius of $2 \mathrm{~cm}$ and a 219 width of approximately $0.50 \mathrm{~cm}$. The aim of these measures is to define the importance of the matrix 220 presence in calcium sulphate rocks.

The conductivity measurement was carried out in accordance with the UNE 21-303-33 regulation (1983) with an electrical circuit in which the samples act as electrical resistance (Figure 4). The electrical power source was a laboratory DC converter power supply with switchable voltage $(0-$ $22432 \mathrm{~V})$ and current (0-10 A). Changes in the amperage above $1 \mathrm{~A}$ do not affect the measurements so an output current of $2 \mathrm{~A}$ has been selected. In order to measure the amperage of the electrical current after traversing the resistance (the sample), an analogue microammenter (Demestres 540) with a range of 0$100 \mu \mathrm{A}$ and an accuracy of $1 \mu \mathrm{A}$, or a nanoammeter (Monroe 285) with a range of $\pm 200 \mathrm{nA}$, a $0.1 \mathrm{nA}$ resolution and an accuracy of $2 \%$ have been used. The potential difference is measured by a voltmeter (MY-67) with a resolution of $0.001 \mathrm{~V}$ connected to both sides of the pills.

The electrodes used on the samples are made of stickers with metallic buttons such as those used for electrocardiograms (Compex). The button has a conductive gel on the sticking side, forming a $0.75 \mathrm{~cm}$-radius circled face (which will be considered the surface of the electrode). This gel is connected directly to the samples. The pills and the electrodes are situated above a paperboard 234 insulator. The barrelling effect is low because the distance between the electrodes is relatively small (approximately $0.50 \mathrm{~cm}$ ) and can be neglected. Due to the difference between the area of the electrodes and the area of the pills, there is a leak path for the electrical current (Roth, 1959). The measurements were made after the reading stabilizes (10 seconds after the power supply is switched on). Polarization causes errors after a certain time in the pills with large fractions of clay. Hence, measurements made after current has flowed for a long time are not considered representative for 240 geophysical surveys because geoelectrical methods use a short current injection time. Each pill has 241 been measured three times, making a total of 6 measurements for each volume fraction. Ohm's law 242 can be applied to calculate the conductivity $(\sigma)$ or resistivity $(\rho)$ of the sample for a known current density $(j)$ and field (E) (Eq. 1): 
It is possible to measure the resistance $(R)$ of the samples. As the thickness $(L)$ of the sample 246 and the surface area of the electrode $(S)$ are known, the electrical resistivity $(\rho)$ can be calculated (Eq. $247 \quad 2)$ :

$$
R=\rho L / S
$$

\subsection{Results and discussion}

The resistivity calculated for the gypsum-lutite and anhydrite-lutite pill sets is shown in Figure

2515 (a full measurements table is shown in Annex 1). The mean resistivity is indicated by symbols 252 together with an error bar representing the standard deviation. The measurements performed on 253 gypsum-lutite pills showed a similar trend to the one presented by Guinea et al. (2010b). The pills ranging from 70 to $100 \%$ in gypsum fraction were more accurate in the present study because the current was measured with a nanoammeter instead of a microammeter. The pills ranging from 0 to $40 \%$ in gypsum fraction displayed a slightly increasing trend of the electrical resistivity (with a mean value ranging from 6 to $33 \Omega$.m). The 50 and $60 \%$ gypsum fraction pills displayed a transitional range of resistivity (with mean values of 72 and $137 \Omega$.m respectively). Finally, the pills with a volume fraction of gypsum ranging from 70 to $100 \%$ displayed a resistivity of $>700 \Omega$.m. The trend shown by the anhydrite pills is similar to the one shown by the gypsum pills for the case of pills with a sulphate fraction from 0 to $50 \%$. There are slight differences between them, but both sets are in the same range of resistivities. The anhydrite-pills with a sulphate fraction of $60 \%$ or above are noticeably more resistive than their equivalent in gypsum pills (ranging from 1012 to 7609 S.m mean resistivity).

It is evident that the grades below $60 \%$ are dominated by the lutitic matrix and the sulphate component affects the measurement negligibly. The sulphate volume fractions above $70 \%$ showed

266 high resistivity values in which the dominant component is the sulphate phase. Between the two 267 differentiated trends there is a transitional zone which represents the loss of the connectivity of the 
matrix. As in the measurements of the gypsum pills by Guinea et al. (2010b), the pills with a large quantity of clay component polarize with measuring time. The chargeability of clay has been widely described before (Takakura, 2006; Deucester and Kaufmann, 2009). lutitic matrix for this case) there is a percolation threshold which represents the minimal quantity of the component required in order to obtain a long-range connectivity (Stauffer and Aharony, 1985).

274 This theory has been widely used to predict characteristics of rocks as the connection of their porosity 275 or fractures (Karmakar et al., 2003; Wang et al., 2007). When the fraction of the component is below 276 the percolation threshold, the cluster is not considered to be connected. In our system the percolation is controlled by conduction through matrix which is much more conductive than the sulphate phase. Anhydrite or gypsum components are dielectric (act as resistances) and they conduct little electrical current while the matrix fraction is above the percolation threshold. Below the percolation threshold, 280 the electrical current finds no connected pathways in the matrix and passes through the sulphates. 281 Hence, the relative proportion of gypsum and anhydrite phases when the presence of matrix is above $28240 \%$, do not affect the electrical resistivity value of the whole rock.

\section{THEORETICAL CALCULATIONS}

\subsection{Methods}

Physical properties of rocks are mainly functions of their microstructure (Guéguen and 287 Palciauskas, 1994). Two important mathematical approaches are effective medium theory (EMT) and percolation theory. The EMT (Kirpatrick, 1973) approximation is quite good for rocks with quasiuniform distributions where only a small degree of heterogeneity is observed, although they cannot

290 describe correctly the phenomenon of clustering (Guéguen et al., 1997) when the heterogeneity is 291 large. Moreover, the knowledge of the geometric distribution and connectivity of the minor phase is of 292 great importance. Percolation theory describes the medium in terms of probabilities of the connectivity 
but does not provide bulk physical properties. Here, we propose a method to determine the physical 294 properties of composite materials that combines the EMT and the percolation theory. On one hand, the EMT is used to calculate the bounds of the physical properties depending on the amount of the matrix phase present. These limits correspond to the two extreme situations where the matrix phase is totally interconnected or disconnected. On the other hand, the percolation theory is used to determine the probability of having a connected or interconnected matrix phase assuming that it is distributed in a single cube distribution.

The effective properties of composites, in particular electrical conductivity, have been studied analytically for a long time for a very simple cases (i.e., Maxwell (1881) used effective medium theory to derive the bulk conductivity of spheres dispersed in a continuous medium). The rocks can be considered as random materials of different property phases at various length scales. To compute the effective properties of such materials requires knowledge of the microstructure and require numerical computation. Garboczi (1999) wrote an algorithm and the consequent FORTRAN code to compute using both finite difference and finite element codes to calculate the electrical an elastic effective properties of materials with different phases from digital images.

In this paper the program ELECFEM2D.F from Garboczi (1999) has been used to compute the effective conductivity of gypsum-anhydrite rock samples. The method to calculate the electrical conductivity of these rocks is to analyze thin section images in which the amount of both anhydrite and gypsum proportion together with the one of the lutitic matrix is known. With this software it is possible to obtain a resistivity distribution model based on a microphotograph.

In order to perform the theoretical calculation of photographs with the program ELECFEM2D.F, the pictures must be converted from an image format file (e.g., JPG, JPEG, GIF, PNG) into an ASCII file. This has been carried out with a converter which creates numerical files from the pixels of the input image. Depending on the color range of these pixels, a numeric value, which is related to a user defined electrical resistivity value, is assigned. As the images used display lutite, gypsum and anhydrite phases; $10,10^{3}$ and $10^{4} \Omega$.m electrical resistivity values have been selected 
respectively. This selection will be discussed further in Section 4.2. The number of variables is user

320 defined and 2 variables ( 1 and 2 ) have been selected for photographs displaying 2 phases (any couple of lutite-gypsum-anhydrite) and 3 variables (1,2 and 3) when the 3 of them are present. Each image was previously treated with an image processing program in order to homogenize the colour ranges in order to improve the detection of each phase.

Once the ASCII file is created, it can be used by the ELECFEM2D.F program. The program divides the surface into $8400(150 \times 56)$ cells with an electrical resistivity value assigned to each one, and calculates the current intensity remaining after crossing the system in the $x$ or $y$ direction. Both directions and the arithmetic mean value have been calculated; the differences are related to the anisotropic distribution of the phases. The selected potential gradient was set to $1 \mathrm{~V} / \mathrm{m}$.

\subsection{Mixing models for two and three phase systems} medium (Glover et al., 2000). In the case of sulphate rocks there is no porosity; hence, the resistivity (or conductivity) of the bulk rock depends on the fraction $(\gamma)$ and the electrical resistivity value $(\rho)$ of each component and on the connectivity and geometrical distribution of the matrix (which has the role of a conducting fluid in a saturated porous medium). Different mixing models (Parallel, Perpendicular,

335 Random, Modified Archie's law and Hashin Shtrickman bounds) have been calculated for the case of 336 two-phase sulphate rocks (gypsum-lutite and anhydrite-lutite) with different proportions of sulphate 337 and matrix. The electrical resistivity values selected for gypsum and lutite phases have been $10^{3}$ and $33810 \Omega . m$, respectively (Guinea et al., 2010b). The electrical resistivity value selected for pure anhydrite 339 phase has been $10^{4} \Omega . \mathrm{m}$, in accordance with the maximum value measured in field examples and the 340 bibliography (Table 2).

342 Palciauskas, 1994) describe the conductivity of a layered distribution of phases with a constant 343 arbitrary thickness arranged axially or normally (in each case) to the current flow. The random model 
344 (Table 3C; Warren and Price, 1961; Shankland and Waff, 1977) describes the bulk conductivity of a 345 material with randomly distributed arbitrary volumes of the conductive phase. Glover (2000) 346 described a mixing model (Table 3D) derived from Archie's law (Archie, 1942), considering the 347 boundary conditions implied by geometrical constrains. To calculate this model, the cementation 348 exponent $m$ has to be defined for each phase. This variable depends on the connectedness of the phases 349 and, as long as in the present case there is no information about this connectedness, it has been tested 350 with different values of $m$ to adjust the data. When the matrix is dominant, $m=0.25$ is consistent with 351 the data obtained for both anhydrite and gypsum pills, which indicates that the structure of the matrix 352 is the same for both types of sample. In the case of pills with higher sulphate fractions, $m=0.01$ and $353 m=0.006$ has been selected for gypsum and anhydrite pills respectively. Hashin and Shtrikman (1963) 354 defined the electrical resistivity value bounds (HS bounds) of a bulk rock from effective medium 355 considerations. These bonds represent the theoretical maximum (upper bound; Table 3E) and 356 minimum (lower bound; Table 3F) electrical resistivity value that any material formed of two different 357 phases with a certain fraction can display.

The mentioned mixing models are displayed in the Figure 6 for both gypsum-lutite (Figure 359 6A) and anhydrite-lutite (Figure 6B) systems. Additionally to the theoretical trends of the mixing 360 models, the resistivities calculated in the laboratory measurements are displayed. The pill samples 361 with a fraction of sulphate phases of $50 \%$ or below show a similar trend to the one displayed by the 362 HS model. This is also shown in the field data in the profiles in which the sulphate formations have a 363 high quantity of matrix within. On the other hand, the resistivity of the pills with a sulphate fraction of $36470 \%$ or above is closer to the perpendicular or $\mathrm{HS}^{+}$models. In the case of the anhydrite pills with high 365 sulphate fraction, they fit better to the random model; but this can be related to the fact that the 366 anhydrite pills are slightly watered during their elaboration. The modified Archie's law also fits well 367 to the laboratory data; the two different trends (low sulphate fractions and high sulphate fractions) 368 have been bridged by means of variations of $m$ in their end ranges (showed as dashed lines in the 369 graphic). The field data obtained in anhydrite rocks indicate that the observed resistivity ranges fit 370 better to the perpendicular or $\mathrm{HS}^{+}$models. The values obtained for the pills with $60 \%$ in sulphate 
371 fraction are transitional, which represents the percolation threshold. Theoretically the percolation 372 threshold occurs in a single phase fraction but in the case of real rocks transitional values are displayed 373 in this range of composition.

From the trends observed for these two-phase systems, it can be considered, as approximation, that the HS bounds define the resistivity of gypsum and anhydrite rocks depending on the quantity of matrix present (modified Archie's law is also a good approximation, but the value of $m$ has to be defined). When the matrix is percolating (sulphate fraction of $50 \%$ or below), the resistivity of the sulphate rocks is bounded to the HS- model. In the case of non percolating matrix (sulphate fraction of $70 \%$ or above), the resistivity is bounded to the $\mathrm{HS}^{+}$model. A general form of the bounds for $n$-phases was given by Berriman (1995). With his formula it is possible to construct a ternary graphic for 3phased rocks (Ledo and Jones, 2005). The gypsum-Anhydrite-Lutite (GAL) system has been calculated for both upper (Table 3G) and lower (Table 3H) HS bounds. In the case of lower bound (Figure 7A), the system is clearly dominated by the lutitic component; the isoresistivity lines are parallel between them showing no appreciable variation in the gypsum-anhydrite axis but when the lutite fraction is less than $10 \%$. The values of resistivity are very low in general, showing less than 100 S.m for a sulphate fraction of $70 \%$. The upper bound (Figure 7B) displays a very different trend dominated by the anhydrite fraction, but in this case the 3 components affect the bulk resistivity value of the rock. The electrical resistivity values are much larger than in the case of lower bound achieving $1000 \Omega$.m with only $40 \%$ of anhydrite. As it has been previously shown, the electrical behavior of the rocks is the one of lower HS bound when the quantity of sulphate is of $50 \%$ or below and the one of upper bound when is of $70 \%$ or above. Thus it is expected that the real distribution of the electrical resistivity for the GAL system should be a combination between the upper and lower HS bounds (Figure 7C).

\subsection{Results and discussion}

In order to check the accurateness of this GAL diagram, the theoretical electrical resistivity value of real thin section rock photographs (Figure 8) has been calculated with ELECFEM2D 
program. Lutitic matrix display brownish colouring while both anhydrite and gypsum have are 398 transparent underplane polarized light; having anhydrite higher relief than gypsum (its bounds are well 399 marked with dark lines). With crossed polarized light, gypsum and anhydrite can be easily 400 differentiated because of the different coloring of the anhydrite (pink, green, blue) in contrast with the gray colors of the gypsum crystals. The standard electrical resistivity values selected for the gypsum, 402 anhydrite and lutitic matrix phases have been $10^{3}, 10^{4}$ and $10 \Omega . \mathrm{m}$ respectively, as has been assigned 403 before. The electrical resistivity of the bulk sections has been measured in both $x$ and $y$ directions; 404 when the distribution of the components is homogeneous these values would be considered similar. 405 For each thin section the fractions of the components are calculated by the program so it is possible to obtain the electrical resistivity value corresponding to these fractions calculated with different mixing models (Table 4). Modified Archie's law has not been calculated for the case of 3-phase system 408 because it would require writing and implementing a numerical inversion program to calculate $m$ and $409 p$ in function of the volume fraction, which is not the aim of this article.

The results show that the mean of the calculated electrical resistivity values in $x$ and $y$ 411 directions are in general close to $\mathrm{HS}^{+}$bound when the fraction of sulphate is $70 \%$ or higher (Figure 8 , 412 thin sections $\mathrm{A}, \mathrm{D}, \mathrm{E}, \mathrm{F}, \mathrm{G}$ and $\mathrm{H}$; Table 4) and to the $\mathrm{HS}^{-}$bound when the fraction of matrix is 413 abundant (Figure 8, B and I; Table 4). There is a good match between the corresponding position of 414 each sample in the figure $7 \mathrm{C}$, according to their components percentages, and the calculated resistivity 415 values. In the case of thin sections $\mathrm{C}$ and $\mathrm{J}$ there is abundant matrix (58 and $52 \%$ respectively); 416 nevertheless, the calculated resistivity values are slightly larger than that expected for such mixture. 417 This is due to that the phases are not scattered and randomly distributed within the samples but 418 forming compact and pure areas. This represents large heterogeneities which change the percolating 419 behavior (we have considered it only for regular distributions of the phases as in the case of the pills) 420 of the bulk rock and makes the transition zone larger. In any case the values are always much closer to 421 the lower bound that to the upper one. The parallel and perpendicular (series) models do not fit well to 422 the calculated resistivities. The random model fits well in many cases but in samples with large 423 fraction of anhydrite, calculated resistivity is too high (especially in $\mathrm{C}$ thin section). 
425 fit to the HS lower bound for compositions of 0-60\% in lutitic matrix. The microscopic anisotropies do not affect to the electrical conductivity of the bulk deposit if we increase the scale. In any case, it is possible to observe cases of heterogeneities at metric scale. When these heterogeneities are large, they can be considered as different rocks (for example a gypsum-rich lutite body within a larger pure gypsum host-rock). In any case, heterogeneities below the detection limit of the method will be considered as a single rock. Another possible case is a layered deposit in which every layer has different purity in the sulphate phase. If the difference among grades is low, which is the most common case, the whole sequence can be considered as a single member with a mean grade. Rarely sulphate deposits have great variations of grade from layer to layer forming a heterogeneous sequence. Sudden variations in the grade exist, but are normally associated with the limit of a sequence or a stable change in the depositional conditions. In the case of having layering between almost pure matrix and highly pure sulphates, the transitional values of resistivity will increase their range as happens in the case of the microphotographs.

\section{GEOELECTRICAL CLASSIFICATION OF CALCIUM SULPHATE ROCKS}

With the GAL diagram obtained combining both $\mathrm{HS}^{+}$and $\mathrm{HS}^{-}$boundaries for a gypsum anhydrite-lutite system (Figure 7C) a geoelectrical classification has been elaborated differentiating 6 calcium sulphate rock types (Figure 9). When the lutitic matrix is connected at long range (in the case of sulphate fraction of $50 \%$ or below) the system is matrix dominant and therefore there is no 444 possibility of differentiating between gypsum and anhydrite components; these rocks are classified as 445 lutites and gypsum/anhydrite rich lutites. The electrical resistivity of this groups range from 10 to 100 $446 \Omega$.m. When the sulphate grade is of $70 \%$ or above, the rock will be considered as pure gypsum when it

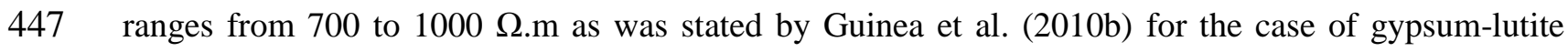
448 systems. If the sulphate mineral is mainly anhydrite (more than 90\%) the rock is considered pure anhydrite and its electrical resistivity value range from 2500 to $10^{4} \Omega . \mathrm{m}$ depending on the rock grade. 
In the case of presence of both gypsum and anhydrite sulphate phases, the rock is considered gypsum 451 with anhydrite (1000 to $2000 \Omega$.m) or anhydrite with gypsum (2000 to $5000 \Omega . m$ ). The values of pure 452 anhydrite and anhydrite with gypsum overlap; in this case it is possible to bond the electrical value to 453 pure anhydrite rocks when there is no evidence of rehydration and to the anhydrite with gypsum 454 otherwise. Between lutites and gypsum/anhydrite rich lutites and the sulphate pure rocks there is a 455 transitional area displaying transitional values from 100 to $700-2500 \Omega$.m (depending on the sulphate 456 composition). The lower boundary of Transitional gypsum/anhydrite rocks has been selected as 55\% 457 in sulphate fraction instead of $60 \%$ because the measures in pills have shown that the $60 \%$ values 458 display an electrical resistivity increasing trend; the upper boundary is $70 \%$ in gypsum fraction. This 459 transitional area is displayed with a resistivity-trend calculated by interpolation between lower and 460 upper HS bounds, but the resistivity in the transition zone is uncertain and therefore the displayed 461 trend is only a reference.

For the microscopic scale, it has been shown that the transitional range is wider (including rocks between 55 and 70\% in sulphate fraction, depending of the anisotropy). For the cases of sulphate

464 fractions of $55 \%$ or below or higher than $70 \%$, the values obtained are similar to the corresponding HS bound. At larger scale, the ERT lines have shown relationships between composition and resistivity values similar to the ones displayed in the classification of the Figure 9; that is, higher than $5000 \Omega . \mathrm{m}$ when the dominant phase is the anhydrite, 1500 to $5000 \Omega . \mathrm{m}$ for different proportions of gypsum and anhydrite (with presence of little lutite) and close to $1000 \Omega$.m when the gypsum is the dominant phase. For deposits with large amount of lutites, the obtained value has been $<60 \Omega$.m in all cases.

\section{CONCLUSIONS}

The electrical properties of calcium sulphate rocks have been widely studied at different scales 473 with microphotographs, synthetic pills and geological deposits. Laboratory tests in pills have shown 474 that the matrix of calcium sulphate rocks may be affected by the percolation phenomena and therefore, 
when the sulphate fraction in a rock is of $55 \%$ or below, the matrix controls the resistivity of the bulk rock. When the sulphate fraction is of $70 \%$ or above, the sulphate minerals control the electrical resistivity of the bulk rock.

The electrical resistivity value of anhydrite rocks range from 10 to $10^{4} \Omega . \mathrm{m}$, being larger in the purest anhydrite rocks. This value is found in the field examples where the anhydrite appears in massive form. The values observed in rocks with both gypsum and anhydrite (with minor matrix) have ranged between 1500 and $5000 \Omega$.m depending on the quantity of each other. Large quantity of matrix in sulphate rocks have shown low electrical resistivity values been unable to differentiate between gypsum and anhydrite.

When the matrix of the calcium sulphate rocks is above the percolation threshold (i.e., more than $45 \%$ ), the electrical resistivity value fits the value calculated with the Hashin-Shtrikman lower bound ( $\left.\mathrm{HS}^{-}\right)$, and when is embedded in the sulphate phase (i.e., 30\% of matrix or less) the resistivity follows the Hashin-Shtrikman upper bound $\left(\mathrm{HS}^{+}\right)$. If there are large heterogeneities in the distribution of the phases, the resistivities of rocks with a matrix quantity ranging from 30 to $45 \%$ can display transitional values (more than $100 \Omega$.m, without reaching values of the purest sulphate rocks). Therefore, it is possible to calculate any combination of these 3 components and the geoelectrical classification has been elaborated for calcium sulphate rocks. With this classification is possible to determine the purity of the sulphates and the presence of anhydrite in gypsum rocks, which is useful for the characterization of the deposit.

\section{ACKNOWLEDGEMENTS}

The present work is a part of a $\mathrm{PhD}$ thesis supported by the "Programa General d'Intensificació de la Recerca" (Generalitat de Catalunya-UB) and the Spanish Government Projects CGL2009-11096, CGL2009-07025, CGL2010-18260 and CGL2009-07604. We want to appreciate the support and facilities of Dr. Albert Casas (Universitat de Barcelona, UB) and Dr. Ricard Bosch 
500 (Universitat Politècnica de Barcelona, UPC). We also want to thank the reviewers of the paper for 501 their interesting comments and particularly to Dr. Paul Glover (University of Leeds) for his detailed 502 review. Finally we want to appreciate the support of Grupo Uralita Corporation, especially to Ms. 503 Mayte Martín, for letting us work in the quarry of Beuda and for their support.

504 REFERENCES: Asfahani, J., Mohamad, R., 2002. Geo-electrical investigation for sulphur prospecting in Teshreen Structure in Northeast Syria. Exploration and Mining Geology, 11, 49-59.

Archie, G.E., 1942. The electrical resistivity log as an aid in determining some reservoir 509 characteristics. Transactions of the American Institute of Mining, Metallurgical, and Petroleum 510 Engineers, 146, 54-62.

Ayora, C., García-Veigas, J., Pueyo, J.J., 1994. The chemical and hydrological evolution of an 512 ancient potash-forming evaporite basin as constrained by mineral sequence, fluid inclusion composition and numerical simulation. Geochimica et Cosmochimica Acta, 58, 3379-3394. 236pp.

Bustillo, M., Calvo, J.P., Fueyo, L., 2001. Rocas Industriales: Tipología, aplicaciones en la 518 construcción y empresas del sector. Rocas y Minerales (ed.). 410pp. 
522 Proceedings of Exploration 97: Fourth Decennial International Conference of Mineral Exploration, 523 A.G. Gubins Ed., 927-940.

Deucester, J.\& Kaufmann, O., 2009. Correlation between inverted chargeabilities and organic compounds concentrations in soils-A field experiment. 15th Near Surface meeting, Dublin, Ireland, Expanded Abstracts, C19.

Furman, A., Ferré, P.A., Warrik, A.W., 2003. A Sensitivity Analysis of Electrical Resistivity Tomography Array Types Using Analytical Element Modeling. Vadose Zone Journal, 2, 416-423.

Garboczi, E.J., 1999. Finite element and finite difference programs for computing the linear electric and elastic properties of digital images of random materials. NIST Internal Report 6269. Also available at http://ciks.cbt.nist.gov/garbocz/ resistivity testing for geotechnical investigation of Pusan clay deposits. Journal of Applied Geophysics, 52, 157-175. 1996. Modelling the Stress/Strain Behaviour of Saturated Rocks Undergoing Triaxial Deformation using Complex Electrical Conductivity Measurements, In Integrated Experimental Measurements and

538 Theoretical Modelling of Rock Transport Properties. Surveys in Geophysics, 17, 307-330. rock physical properties. Tectonophysics, 279, 23-35. 
544 University Press, Princenton, NJ, 294pp.

546 supporting glauberite deposits evaluation in the Montes de Torrero area (Zaragoza). Geogaceta, 47, $547 \quad 145-148$.

Guinea, A., Playà, E., Rivero, L., Himi, M., 2010a. Electrical Resistivity Tomography and 549 Induced Polarization techniques applied to the identification of gypsum rocks. Near Surface 550 Geophysics, 8, 249-257.

Gypsum Rocks. Surveys in Geophysics, 31 (6), 557-580.

Hashin, Z., Shtrikman, S., 1963. A variational approach to the theory of the elastic behavior of 554 multiphase materials. Journal of the Mechanics and Physics of Solids, 11, 12-140.

Holliday, D.W., 1970. The petrology of secondary gypsum rocks: a review. Journal of 556 Sedimentary Petrology, 40, 734-744.

558 Geochemical methods in alabaster provenance: an application example. IX ASMOSIA:

559 Interdisciplinary Studies on Ancient Stone meeting, Tarragona, Spain, Abstracts 125. 
Klein, C., Hurlburt, C.S., 1998. Manual de mineralogía de Dana. Reverté, 438pp. composition, electrical conductivity laboratory studies and magnetotelluric field observations: Application to the intermontane belt, Northern Canadian Cordillera. Earth and Planetary Science Letters, 236, 258-268. pseudosections by a quasi-Newton method. Geophysical Prospecting, 44, 131-152. Journal of Geophysical Research, 90, 7837-7847. formaciones evaporíticas. Geogaceta, 44, 223-226. an ERT system. Chemical Engineering Science, 52, 2197-2203. $540 \mathrm{pp}$.

Ortí, F., 2000. Unidades glauberíticas del Terciario ibérico: nuevas aportaciones. Revista de la 582 sociedad geológica de España, 13, 227-249. 422. 
590 the priabonian potash basin (Later Eocene: Autochthonous-Allochthonous Zone). In: Busson, G., 591 Schreiber, Ch. Eds. Sedimentary deposition in rift and foreland basins in France and Spain. Columbia 592 University Press, New York, 358-387. Near Surface Geophysics, 8, 173-180. Prensas Universitarias de Zaragoza, 72pp. upper mantle. Journal of Geophysical Research, 82, 5409-5417. 55. 604 systems. Elsevier, Amsterdam, 257pp. $606 \quad 181 \mathrm{pp}$. 
610 contact method of nonpolarizable electrodes on a base rock and detection of clay minerals by 611 normalised chargeability. Geophysical Exploration, 59, 363-370.

613 y superficial de los materiales aislantes eléctricos sólidos. Instituto Español de Normalización.

614 Wang, K.W., Sun, J.M., Guan, J.T., Zhu, D.W., 2007. A percolation study of electrical 615 properties of reservoir rocks. Physica A, 380, 19-26.

617 Engineers Journal, 1, 153-169. 
621 Table 1: Geoelectrical classification of gypsum rocks (modified after Guinea et al. 2010b).

622 Table 2: Electrical resistivity values for anhydrite rocks in the literature.

623 Table 3: Summary of the equations of the mixing models used in the present study (modified from

624 Glover et al., 2000).

625 Table 4: Results of the theoretical calculations of electrical resistivity of the thin section photographs 626 with ELECFEM2D software. Parallel, Series, Random, Archie's modified law and Lower (HS') and 627 upper $\left(\mathrm{HS}^{+}\right)$Hashin-Shtrikman bounds have been calculated, only considering the proportion of each 628 phase. The calculated resistivity for each sample in both $x^{-}$and $y^{-}$directions is listed in the right 629 column. The corresponding images of the thin sections A to $\mathrm{J}$ are displayed in Figure 8.

\section{FIGURE CAPTIONS}

632 Figure 1: Photographs of the areas studied with ERT, A to C are taken in the Beuda quarry while D is 633 taken in the area of Odena and $\mathrm{E}$ in the Zaragoza formation. A) pure gypsum-anhydrite boundary with 634 a interdigitation between them; B) sulphate layers showing less gypsum fraction than in other areas; 635 C) anhydrite blocks filled with gypsum veins and embedded in a gypsum matrix; D) massive anhydrite 636 body; E) impure sulphate layers in Montes de Torrero area.

637 Figure 2: Distribution of evaporite formations in the Tertiary basins northeastern Spain indicating the 638 location of the nine studied ERT profiles with black dots (modified from Ortí et al., 2010).

639 Figure 3: Inverted electrical resistivity tomography data for the different areas studied (the locations 640 of the profiles are shown in figure 2). Profile F modified from Guinea et al. (2010b). 
641 Figure 4: Electrical circuit to measure the electrical resistivity of the samples. It consists of a 642 switchable laboratory power-supply (EA-PS 3032-10B), two electrodes, a voltmeter (MY-67) and a 643 micro- or nanoammeter depending on the samples (Demestres 540 and Monroe 285, respectively).

644 Figure 5: Semi-logarithmic plots representing the results of the measurements of gypsum-lutite (A) 645 and anhydrite-lutite (B) pills. The symbols represent the mean of the calculated resistivities for each 646 sulphate fraction (calculated from a total of 6 measurements for every fraction) and the error bar 647 represents the standard deviation. The error on the $\mathrm{X}$ axis is not showed because is below $1 \%$.

648 Figure 6: Different mixing models calculated for the case of gypsum-lutite (A) and anhydrite-lutite 649 rocks (B). The dashed lines in the modified Archie's model represent the transition between the low 650 sulphate fraction and high sulphate fraction trends. The resistivity ranges obtained in the laboratory 651 essays (Figure 5) are superimposed for both cases.

652 Figure 7: Ternary plots showing Hashin-Shtrikman bounds for gypsum-anhydrite-lutite (GAL) 653 system. A) lower HS bound; B) upper HS bound; C) combined diagram considering the percolation 654 phenomena.

655 Figure 8: Microphotographs of thin sections of calcium sulphate rocks; D, E, H and I are taken with 656 cross-polarized light and the rest with plane polarized light. The different phases are indicated with 657 numbers 1 (gypsum), 2 (anhydrite) and 3 (lutite/carbonate).

658 Figure 9: Geoelectrical classification of calcium sulphate rocks, depending on their gypsum659 anhydrite-lutite fraction. The resistivity values are shown in the background (Figure 7C).

\section{ANNEX}

663 Annex 1: Results of the laboratory measurements on synthetic pills made by mixing powdered pure 664 anhydrite or gypsum with clay. G samples correspond to gypsum-lutite pills, while A samples 665 correspond to anhydrite-lutite pills. Samples with a sulphate fraction of $70 \%$ or above have been 
666 measured with a nanoammeter and the rest with a microammeter. The mean resistivity for each 667 fraction and the standard deviation is showed in Figure 5. 


\title{
THE ELECTRICAL PROPERTIES OF CALCIUM SULPHATE ROCKS FROM DECAMETRIC TO MICROMETRIC SCALE
}

\author{
UNCHANGED FIRST REVISION (second revision is placed after this one)
}

\author{
Ander Guinea $^{1 *}$, Elisabet Playà ${ }^{1}$, Lluís Rivero ${ }^{1}$, Juan José Ledo ${ }^{2}$, Pilar Queralt ${ }^{2}$
}

\author{
${ }^{l}$ Departament de Geoquímica, Petrologia i Prospecció Geològica. Facultat de Geologia, Universitat de Barcelona (UB). \\ Martí i Franquès s/n, 08028 Barcelona, Spain. \\ ${ }^{2}$ Departament de Geodinàmica i Geofísica. Facultat de Geologia, Universitat de Barcelona (UB). Martí i Franquès s/n, \\ 08028 Barcelona, Spain. \\ E-mails: anderguinea@ub.edu; eplaya@ub.edu; lrivero@ub.edu; jledo@ub.edu; pilar.queralt@ub.edu \\ *Corresponding author: Phone number: +34 9340311 65. Fax number: +34 934021417
}

\section{ABSTRACT}

Sulphate rocks have a sedimentary evaporitic origin and are present in many deposits worldwide. Among them, gypsum (dihydrated calcium sulphate) is the most common and is exploited for industrial purposes. Anhydrite (calcium sulphate) is frequently found in gypsum quarries and in non-outcropping sulphates. The greater hardness of anhydrite compared to gypsum causes a problem for gypsum extraction; quarry fronts have to be halted as soon as anhydrite is found. In this work the electrical properties of calcium sulphates have been studied by means of geoelectrical methods.

and their lithological composition has been established with the lutitic matrix being the main controlling factor when it is well connected. When the matrix is under the percolation threshold the sulphate phases are dominant, and the electrical response of the rocks depends on the percentage of each phase. When the rock is matrix dominant, the electrical resistivity trend fits with the Hashin- 
26 Shtrikman lower bound for multiphase systems (considering gypsum, anhydrite and matrix as the 27 components). On the other hand, when the rock is calcium sulphate dominant the trend shows the one 28 of the Hashin-Shtrikman upper bound. The reference electrical resistivity value of pure anhydrite 29 rocks has been defined as $10^{4} \Omega . \mathrm{m}$ and geoelectrical classification for calcium sulphate rocks has been 30 elaborated. With this classification it is possible to differentiate between calcium sulphate rocks with 31 different composition from their electrical resistivity value. This classification has been checked with 32 field examples and calculating the theoretical resistivity value of thin section photographs with the 33 program ELECFEM2D. The electrical behavior of calcium sulphate rocks is a good reference for other 34 type of rocks with electrically differentiated components, and similar methods can be used to define 35 their geoelectrical responses. 


\section{INTRODUCTION}

Evaporites are sedimentary rocks originated from evaporation of salty water. Sulphates are one of the principal groups of evaporitic rocks and the principal sulphate minerals are: gypsum $\left(\mathrm{CaSO}_{4} \cdot 2 \mathrm{H}_{2} \mathrm{O}\right)$, anhydrite $\left(\mathrm{CaSO}_{4}\right)$, glauberite $\left(\mathrm{Na}_{2} \mathrm{Ca}\left(\mathrm{SO}_{4}\right)_{2}\right)$ and thenardite $\left(\mathrm{Na}_{2} \mathrm{SO}_{4}\right)$ (Warren, 2006).

Texturally, sulphate rocks are mainly crystalline; but may appear with clastic textures when they are reworked. They retain only a reduced primary porosity $(<1 \%)$, display a restricted mineralogical (and geochemical) composition and can appear combined with a lutitic matrix (mainly composed of clay and microcrystalline carbonates). These rocks are extensively affected by diagenetic processes which can change their texture into microcrystalline. Gypsum tends to transform to anhydrite when buried because of dehydration, and the opposite process also takes place when anhydrite is affected by weathering and superficial waters (Holliday, 1970).

Gypsum deposits are exploited for industrial purposes. It is mainly used in construction as drywall and as an ingredient for plaster, but it is also used in other industries (Bustillo et al., 2001). Gypsum quarries occur worldwide, with the USA and Iran as the largest producers. One of the most important problems found while quarrying gypsum is the presence of anhydrite. By comparison with gypsum, anhydrite is harder and denser. The drilling machines can be damaged by anhydrite bodies. Hence, the exploitation must be stopped immediately. Anhydrite is also used by industry for different purposes, but because of the exploitation difficulties it is mainly obtained by dehydration of previously extracted gypsum. Anhydrite (from gypsum dehydration) is commonly found deeply buried (until 5001000 m; Shearman, 1985; Warren, 2006). It rarely crops out because it tends to hydrate and transform into gypsum. resistivity tomography (ERT) is a geophysical technique which can be used to obtain an image of the electrical resistivity distribution of the subsurface. For this purpose an array of metal electrodes are planted in the soil and the difference of electrical potential is measured between pairs of them while a direct current (DC) is passed between two others. The arrangement of these 4 electrodes depends on 
the electrical array that has been selected and the measurement is repeated along the string of electrodes at different spacings and positions. The apparent resistivity values obtained are inverted into resistivity values as a function of depth and position using inversion software (RES2DINV, Geotomo Software, ver. 3.5). This method is a rapid, non invasive and relatively low-cost.

Gypsum deposits have been successfully identified with ERT profiles (Lugo et al., 2008; Guinea et al., 2009; Guinea et al., 2010a). Guinea et al. (2010b) produced a geoelectrical classification of gypsum rocks establishing a direct relation between their electrical resistivity value and the percentage of lutitic matrix (Table 1). In that study the anhydrite phase was not considered, but this mineral very often appears in gypsum rocks. The scientific literature shows anhydrite to have a large range of resistivities from <100 to $10^{10}$ S.m (Table 2; Jakosky, 1950; Parkhomenko, 1967; Rider, 1986; Robison and Çoruh, 1988; Choteau et al., 1997; Asfahani and Mohammad, 2002; Lugo et al., 2008). The variation in the electrical resistivity value of anhydrite in these publications is related to the presence of gypsum, but the influence of the lutitic matrix is not mentioned.

The aim of this study is to measure the electrical resistivity of pure anhydrite at zero frequency and to establish the effect of compositional variations in the gypsum-anhydrite-lutite rock system. This problem will be studied from three different angles, namely numerical modeling, laboratory measurements and field data. The information thus obtained should help to interpret geoelectrical data in future surveys on sulphate rocks.

\section{FIELD DATA}

\subsection{Geological setting}

During the Lutetian (Middle Eocene) a large marine evaporitic sequence was deposited in the South Pyrenean Foredeep (Rosell and Pueyo, 1997). In the La Garrotxa area (eastern Pyrenees) secondary gypsum (as product of the hydration of anhydrite) crops out extensively and anhydrite has 
been found in borehole logs with other evaporitic rocks such as halite (Carrillo, 2009). Close to the village of Beuda (Girona, Spain) there is a quarry in which gypsum has been exploited since at least the 1930s. There are many sculptures made of alabaster (pure secondary microcrystalline gypsum) from the Middle Ages for which geochemical analysis has demonstrated that they were extracted from the Beuda gypsum unit (Inglés et al., 2009).

Nowadays the quarry has been largely developed and anhydrite crops out in many places and where the exploitation has consequently been stopped. The gypsum of the Beuda unit was produced by hydration of anhydrite and therefore there are still some anhydrite relict bodies embedded in the gypsum. In the walls of the quarry it is possible to observe boundaries between gypsum and anhydrite usually displaying a quite pure anhydrite core and a transition to pure gypsum (Figure 1A). The purity of the calcium sulphate varies from higher than $90 \%$ to close to $75 \%$ in certain layers (Figure 1B). The changes in the purity of both gypsum and anhydrite rocks and the complex geometrical relations between them make these deposits very heterogeneous. In some cases matrix bearing gypsum appears in contact with pure anhydrite and in other cases the anhydrite does not appear as a body but as fragments embedded in gypsum and filled with gypsum veins (Figure 1C). In other places anhydrite appears massive with little gypsum within (Figure 1D). Three ERT profiles (figure 2, A, B, and C) have been performed in the Beuda gypsum quarry. Profile D (Figure 2D) has been performed in the same formation of the Beuda quarry, close to the village of Serinyà. In the area studied there are sulphate layers under a soil. In the nearby outcrops pure secondary gypsum appears, but at depth, the sulphates probably transform into anhydrite as it has been observed in the region (Carrillo, 2009).

Marine evaporitic deposition took place during the upper Eocene on the Catalan margin of the Ebro basin (Ayora et al., 1994). The Odena gypsum unit was extensively exploited during the $20^{\text {th }}$ century and there are many abandoned quarries in the region. Profile E has been carried out in an abandoned quarry near to the village of Odena where anhydrite crops out (Figure 2E).

In the Montes de Torrero area (Zaragoza, Spain) there is a Miocene evaporitic formation hundreds of meters thick. The area has been studied by means of boreholes in which gypsum, 
116 anhydrite, glauberite and halite were found among other minerals. This formation has a large quantity

117 of matrix in every layer (Ortí, 2000; Salvany, 2009). The outcropping materials are mainly gypsum,

118 which formed from the hydration of anhydrite or glauberite (Figure 1E), and more than 50\% matrix 119 (composed of clay and marl). An ERT survey has been performed where borehole B4 was drilled 120 (Figure 2F). The $\log$ of the borehole shows gypsum to a depth of $35 \mathrm{~m}$, then glauberite to a depth of 69 $121 \mathrm{~m}$ followed by anhydrite to $80 \mathrm{~m}$ with some interbedded layers of halite or glauberite (Salvany, 2009).

122 The whole log shows significant fractions of matrix at all depths as such as at the surface.

A total of six ERT profiles have been carried out at anhydrite rock deposit areas in the South Pyrenean Foredeep and Ebro Basin (North East of Spain; Figure 3). The examples are presented below starting with those performed in quarries (Figure 3; A, B, C and D) and afterwards in areas with no evaporites that crop out (Figure 3; E and F). All the profiles performed in quarries show a high fraction of sulphates and therefore relatively high electrical resistivity values.

A Syscal Pro Switch ERT system with 48 electrodes and an external power supply has been used to carry out the data acquisition. The electrode spacing for the measurements in quarries was 0.5 ,

1311.5 or $2 \mathrm{~m}$ depending on the local conditions. In the profiles performed where no evaporates crop out,

132 the electrode spacing was $10 \mathrm{~m}$ to increase the depth of investigation because anhydrite deposits tend 133 to appear below other formations (because at shallow depth they transform into gypsum). The used 134 electrodes for the data acquisition were made of stainless steel and they were nailed in the terrain by means of hammers. There are many possible array configurations in geophysical prospection (Ma et al., 1997; Furman et al., 2003; Szalai and Szarka, 2008) which may be applied to anhydrite rocks. The

137 Wenner-Schlumberger and Dipole-Dipole arrays have been selected depending of the structure under 138 study, and the Dipole-Dipole has been used were lateral electrical resistivity changes are important.

139 The apparent resistivity data of performed ERT profiles has been inverted with the RES2DINV 140 program; that is available from 1995 (Loke and Barker, 1996). The inversion process has been carried 141 out with 5 iterations for each profile. With this number of iterations the data converges in all cases 
achieving an acceptable RMS error. Additional iterations do not vary the RMS error significantly but

143 increase the electrical resistivity value in the low sensitivity areas (i.e., the pure sulphate rocks). As

144 explained later in Section 2.3, the resistivity range calculated (with 5 iterations) in pure anhydrite

145 bodies at depth is alike to the apparent resistivity measured in shallow pure anhydrite rocks. their composition. The samples have been powdered and $0.5 \mathrm{~g}$ from each one has been dissolved in

$148250 \mathrm{ml}$ of distilled water in accordance with the solubility of calcium sulphate in water. The solutions

149 were shaken for 24 hours and then filtered. The residue left after filtering correspond to the non-

150 soluble phases, which are made up of the lutitic matrix (including carbonates, quartz and other minor

151 accompaining minerals). The residue was weighted in order to estimate the fraction of the in sulphate 152 phases.

In the Beuda quarry some different areas have been studied. The profiles A and B have been performed upon areas in which massive anhydrite was found and afterwards was buried under quarry waste materials. The profiles were spread above the infilling. The result of the inversion for Profile A (Figure 3A) display an upper part with relatively low electrical resistivity values (between 10 and 200 $\Omega . m)$, which corresponds to the quarry waste. Underlying these materials there is a homogeneous body with high resistivity value (up to $10^{4} \Omega . \mathrm{m}$ ), which has been interpreted as pure anhydrite (Lugo et al.,

160 2008). In the case of Profile B, which was performed perpendicularly to Profile A, the inverted resistivity section (Figure 3B) displays a lateral electrical resistivity variation below the quarry waste

162 layer. A well was drilled in the middle of profile B and high hardness was found at 6 meter depth, but 163 no core was recovered. This hardness has been interpreted as anhydrite rock with certain quantity of 164 matrix. 
167 both anhydrite and gypsum appeared in the ground surface. In the inverted resistivity section (Figure

$1683 \mathrm{C}$ ) there is displayed a lateral variation of electrical resistivity ranging from $10^{3}$ to $10^{4} \Omega$.m. The 169 larger resistivity values are limited with the outcropping of massive anhydrite, while the lower ones 170 are related to the presence of gypsum, and the intermediate values correspond to the transition between 171 the two pure phases.

Profile D has been performed in an abandoned quarry near to the village of Odena where anhydrite crops out. The inverted section (Figure 3D) shows electrical resistivities ranging from $10^{3}$ to

$17410^{4} \Omega . \mathrm{m}$, similarly to the observations in the Beuda quarry. In the areas in which the value is larger, 175 massive anhydrite is observed. Lower electrical resistivity than 500 S.m are related to lutitic 176 sedimentary layers. profile (Figure 3E) displays a shallow deposit with a low electrical resistivity value (50 $\Omega . \mathrm{m})$ which corresponds to the underlying materials. Below this layer there is a high resistivity body ranging from

1801000 to more than $5000 \Omega . \mathrm{m}$ and with a more conductive structure in the central part (between 100 181 and $200 \Omega . \mathrm{m})$. This structure represents a fault present in the area, and identified on the surface by 182 geological evidence (Carrillo, 2009).

The profile F performed in Montes de Torrero area has been modified from Guinea et al.

184 (2010b). In the inverted image (Figure 3F) the whole deposit shows a general trend of 30-50 $\Omega . m$ with some bodies slightly more resistive (up to $300 \Omega . \mathrm{m}$ at the most resistive points). Those bodies would represent a higher grade of the deposit (up to $60 \%$ in sulphates) in these zones, this grade changes are related to primary depositional processes and they are very common in these materials (Guinea et al.,

188 2010a). In any case it is not possible to differentiate between anhydrite and gypsum layers because the 189 electrical behavior of the deposit is dominated by the abundant matrix. 
192 for pure anhydrite rocks because in some profiles in which some of the shallowest points have been

193 measured almost directly above massive anhydrite rocks, show an apparent resistivity value larger 194 than $5000 \Omega$.m. In these cases the apparent and the inverted resistivities are similar but a slightly lower 195 for the apparent resistivity because the electrodes are inserted into a thin clay layer. When these rocks 196 are mixed with gypsum forming pure sulphate rocks with both phases, which are the most common in 197 the quarries, they display an intermediate value of resistivity ranging from 1500 to $5000 \Omega . \mathrm{m}$ 198 depending on the quantity of each phase. As the distribution of the anhydrite in the gypsum deposits is 199 very heterogeneous due to the rehydration processes, the tomography lines show heterogeneous bodies 200 with different electrical resistivity values and transitional zones. Values close to $1000 \Omega . \mathrm{m}$ are related 201 to the purest gypsum rocks or to pure anhydrite with a significant quantity of matrix rocks. When the matrix has a large volume fraction, it is not possible to differentiate is gypsum from anhydrite with 203 ERT. In these cases, the rocks will display a resistivity below $100 \Omega$.m, which is significantly lower 204 than the resistivity of sulphate-rich deposits. The low electrical resistivity of sulphate deposits with 205 large matrix volume fraction was studied further by Guinea et al. (2010b) for the case of gypsum rocks 206 (without anhydrite).

\section{LABORATORY MEASUREMENTS}

\subsection{Methods}

Many authors have measured the electrical conductivity of geological materials (Keller, 1966;

211 Lockner and Byerlee, 1985; Guéguen and Palciauskas, 1994; Glover et al. 1996; Giao et al., 2003; 212 Rusell and Barker, 2010; among others). Guinea et al (2010b) made eleven gypsum-clay pills in 213 different proportions with a range from 0 to $100 \%$ of $\mathrm{CaSO}_{4} \cdot \mathrm{H}_{2} \mathrm{O}$ at intervals of $10 \%$ in composition 214 and measured their electrical conductivity. Three sets of eleven anhydrite-lutite pills and three sets of 215 gypsum-lutite pills have been made using the same methodology, parameters and resources. The 216 compositional error of the pills is below $1 \%$, because the weigh corresponding to the volume of each 
217 fraction has been measured with a precision scale (mod. Sarorius B3100S) with a resolution of $0.01 \mathrm{~g}$ 218 (the pills have a total weight of $13.5 \mathrm{~g}$ ). The pills have a cylindrical shape with a radius of $2 \mathrm{~cm}$ and a 219 width of approximately $0.50 \mathrm{~cm}$. The aim of these measures is to define the importance of the matrix 220 presence in calcium sulphate rocks

The conductivity measurement was carried out in accordance with the UNE 21-303-33 regulation (1983) with an electrical circuit in which the samples act as electrical resistance (Figure 4). The electrical power source was a laboratory DC converter power supply with switchable voltage $(0-$ $32 \mathrm{~V})$ and current $(0-10 \mathrm{~A})$. Changes in the amperage above $1 \mathrm{~A}$ do not affect the essays so an output current of $2 \mathrm{~A}$ has been selected. In order to measure the amperage of the electrical current after traversing the resistance (the sample), an analogical microammenter (Demestres, mod. 540) with a range of $0-100 \mu \mathrm{A}$ with an accuracy of $1 \mu \mathrm{A}$ or a nanoammeter (Monroe, mod. 285) with a range of $\pm 200 \mathrm{nA}$ and $0.1 \mathrm{nA}$ resolution and an accuracy of $2 \%$ have been used. The potential difference is measured by a voltimeter (MY-67) with a resolution of $0.001 \mathrm{~V}$ connected to both sides of the pills. The electrodes used on the samples are made of stickers with metallic buttons as the ones used for 231 electrocardiograms. The button has a conductive gel in the sticking side, forming a $0.75 \mathrm{~cm}$-radius 232 circled face (which will be considered the surface of the electrode). This gel is directly connected to 233 the samples. The pills and the electrodes are situated above a paperboard insulator. The barreling 234 effect is low because the distance between the electrodes is relatively small (approximately $0.50 \mathrm{~cm}$ ). 235 Due to the difference between the area of the electrodes and the area of the pills, there is a leak path 236 for the electrical current (Roth, 1959). The measurements were made after the reading stabilizes (10 237 seconds after the power supply is switched on). Polarization causes errors after a certain time in the 238 pills with large fractions of clay. The longest time measures are not considered representative for 239 geophysical surveys because geoelectrical methods use a short current injection time. Each pill has 240 been measured three times, making a total of 6 measurements for each volume fraction. Ohm's law 241 can be applied to calculate the conductivity $(\sigma)$ or resistivity $(\rho)$ of the sample for a known current density $(j)$ and field $(E)$ (Eq. 1): 


$$
j=\sigma E=E / \rho
$$

It is possible to measure the resistance $(R)$ of the samples. As the thickness $(L)$ of the sample and the surface area of the electrode $(S)$ are known, the electrical resistivity $(\rho)$ can be calculated (Eq.

$$
R=\rho L / S
$$

\subsection{Results and discussion}

The resistivity calculated for the gypsum-lutite and anhydrite-lutite pill sets is shown in Figure

2505 (full measurements table is shown in Annex 1). The mean resistivity is indicated by symbols 251 together with an error bar representing the standard deviation. The measures performed on gypsum252 lutite pills showed a similar trend to the one presented by Guinea et al. (2010b). The pills ranging from 70 to $100 \%$ in gypsum fraction were more accurate in the present study because the current was measured with a nanoammeter instead a microammeter. The pills ranging from 0 to $40 \%$ in gypsum fraction displayed a slightly increasing trend of the electrical resistivity (with a mean value ranging from 6 to $33 \Omega$.m). The 50 and $60 \%$ gypsum fraction pills displayed a transitional range of resistivity (with mean values of 72 and $137 \Omega . m$ respectively). Finally, the pills with a volume fraction of gypsum ranging from 70 to $100 \%$ displayed a resistivity of $>700 \Omega . \mathrm{m}$. The trend showed by the anhydrite pills is similar to the one showed by the gypsum pills for the case of pills with a sulphate fraction from 0 to $50 \%$. There are slight differences between them, but both sets are in the same range of resistivities. The anhydrite-pills with a sulphate fraction of $60 \%$ or above are noticeably more resistive than their equivalent in gypsum pills (ranging from 1012 to $7609 \Omega$.m in mean resistivity).

It is evident that the grades below $60 \%$ are dominated by the lutitic matrix and the sulphate 264 component affects the measurement negligibly. The sulphate volume fractions above $70 \%$ showed 265 high resistivity values in which the dominant component is the sulphate phase. Between the two 266 differentiated trends there is a transitional zone which represents the loose of the connectivity of the 
matrix. As in the measures of gypsum pills by Guinea et al. (2010b), the pills with large quantity of clay component polarize with measuring time. The chargeability of clay has been widely described before (Takakura, 2006; Deucester and Kaufmann, 2009).

Percolation theory states that in a cluster with a component randomly distributed (meaning the lutitic matrix for this case) there is a percolation threshold which represent the minimal quantity of the component required in order to obtain a long-range connectivity (Stauffer and Aharony, 1985). This theory has been widely used to predict characteristics of rocks as the connection of their porosity or

274 fractures (Karmakar et al., 2003; Wang et al., 2007). When the fraction of the component is below the 275 percolation threshold, the cluster is not considered to be connected. In our system the percolation is controlled by conduction through matrix which is much more conductive than the sulphate phase. Anhydrite or gypsum components are dielectric (act as resistances) and they conduct little electrical current while the matrix fraction is above the percolation threshold. Below the percolation threshold, the electrical current finds no connected pathways in the matrix and passes through the sulphates.

280 Hence, the relative proportion of gypsum and anhydrite phases when the presence of matrix is above $28140 \%$, do not affect the electrical resistivity value of the whole rock.

\section{THEORETICAL CALCULATIONS}

\subsection{Methods}

Physical properties of rocks are mainly functions of their microstructure (Guéguen and Palciauskas, 1994). Two important mathematical approaches are effective medium theory (EMT) and percolation theory. The EMT (Kirpatrick, 1973) approximation is quite good for rocks with quasiuniform distributions where only a small degree of heterogeneity is observed, although they cannot

289 describe correctly the phenomenon of clustering (Guéguen et al., 1997) when the heterogeneity is 290 large. Moreover, the knowledge of the geometric distribution and connectivity of the minor phase is of 291 great importance. Percolation theory describes the medium in terms of probabilities of the connectivity 
292 but does not provide bulk physical properties. Here, we propose a method to determine the physical 293 properties of composite materials that combines the EMT and the percolation theory. On one hand, the 294 EMT is used to calculate the bounds of the physical properties depending on the amount of the matrix phase present. These limits correspond to the two extreme situations where $t$ he matrix phase is totally interconnected or disconnected. On the other hand, the percolation theory is used to determine the probability of having a connected or interconnected matrix phase assuming that it is distributed in a 298 single cube distribution.

The effective properties of composites, in particular electrical conductivity, have been studied analytically for a long time for a very simple cases (i.e., Maxwell (1881) used effective medium theory to derive the bulk conductivity of spheres dispersed in a continuous medium). The rocks can be considered as random materials of different property phases at various length scales. To compute the effective properties of such materials requires knowledge of the microstructure and require numerical computation. Garboczi (1999) wrote an algorithm and the consequent FORTRAN code to compute using both finite difference and finite element codes to calculate the electrical an elastic effective properties of materials with different phases from digital images.

In this paper the program ELECFEM2D.F from Garboczi (1999) has been used to compute the effective conductivity of gypsum-anhydrite rock samples. The method to calculate the electrical conductivity of these rocks is to analyze thin section images in which the amount of both anhydrite and gypsum proportion together with the one of the lutitic matrix is known. With this software it is possible to obtain a resistivity distribution model based on a microphotograph.

In order to perform the theoretical calculation of photographs with the program 313 ELECFEM2D.F, the pictures must be converted from an image format file (e.g., JPG, JPEG, GIF, 314 PNG) into an ASCII file. This has been carried out with a converter which creates numerical files from 315 the pixels of the input image. Depending on the color range of these pixels, a numeric value, which is 316 related to a user defined electrical resistivity value, is assigned. As the images used display lutite, gypsum and anhydrite phases; $10,10^{3}$ and $10^{4} \Omega$.m electrical resistivity values have been selected 
respectively. This selection will be discussed further in Section 4.2. The number of variables is user

319 defined and 2 variables ( 1 and 2 ) have been selected for photographs displaying 2 phases (any couple 320 of lutite-gypsum-anhydrite) and 3 variables (1,2 and 3) when the 3 of them are present. Each image was previously treated with an image processing program in order to homogenize the color ranges in order to improve the detection of each phase.

Once the ASCII file is created, it can be used by the ELECFEM2D.F program. The program divides the surface into $8400(150 \times 56)$ cells with an electrical resistivity value assigned to each one, and calculates the current intensity remaining after crossing the system in the $x$ or $y$ direction. Both directions and the arithmetic mean value have been calculated; the differences are related to the anisotropic distribution of the phases. The selected potential gradient was set to $1 \mathrm{~V} / \mathrm{m}$.

\subsection{Mixing models for two and three phase systems}

Many mixing models have been published in order to predict the bulk conductivity of a porous medium (Glover et al. 2000). In the case of sulphate rocks there is no porosity; hence, the resistivity (or conductivity) of the bulk rock depends on the fraction $(\gamma)$ and the electrical resistivity value $(\rho)$ of each component and on the connectivity and geometrical distribution of the matrix (which has the role of a conducting fluid in a saturated porous medium). Different mixing models (Parallel, Perpendicular,

334 Random, Modified Archie's law and Hashin Shtrickman bounds) have been calculated for the case of 335 two-phase sulphate rocks (gypsum-lutite and anhydrite-lutite) with different proportions of sulphate 336 and matrix. The electrical resistivity values selected for gypsum and lutite phases have been $10^{3}$ and $33710 \Omega . m$, respectively (Guinea et al., 2010b). The electrical resistivity value selected for pure anhydrite 338 phase has been $10^{4} \Omega . \mathrm{m}$, in accordance with the maximum value measured in field examples and the bibliography (Table 2).

341 Palciauskas, 1994) describe the conductivity of a layered distribution of phases with a constant 342 arbitrary thickness arranged axially or normally (in each case) to the current flow. The random model 
343 (Table 3C; Warren and Price, 1961; Shankland and Waff, 1977) describes the bulk conductivity of a

344 material with randomly distributed arbitrary volumes of the conductive phase. Glover (2000) 345 described a mixing model (Table 3D) derived from Archie's law (Archie, 1942), considering the 346 boundary conditions implied by geometrical constrains. To calculate this model, the cementation 347 exponent $m$ has to be defined for each phase. This variable depends on the connectedness of the phases 348 and, as long as in the present case there is no information about this connectedness, it is considered 349 that $m_{l}=m_{2}=1$. Hashin and Shtrikman (1963) defined the electrical resistivity value bounds (HS 350 bounds) of a bulk rock from effective medium considerations. These bonds represent the theoretical 351 maximum (upper bound; Table 3E) and minimum (lower bound; Table 3F) electrical resistivity value 352 that any material formed of two different phases with a certain fraction can display. 6A) and anhydrite-lutite (Figure 6B) systems. The modified Archie's law model has the same trend that is calculated for the case of parallel model; this is because the cementation exponent $m$ is considered 1 for every phase. Additionally to the theoretical trends of the mixing models, the resistivities calculated in the laboratory measurements are displayed. The pill samples with a fraction of sulphate phases of $50 \%$ or below show a similar trend to the one displayed by the $\mathrm{HS}^{-}$model. This is also shown in the field data in the profiles in which the sulphate formations have a high quantity of matrix within. In the other hand, the resistivity of the pills with a sulphate fraction of $70 \%$ or above is 361 closer to the perpendicular or $\mathrm{HS}^{+}$models. In the case of the anhydrite pills with high sulphate 362 fraction, they fit better to the random model; but this can be related to the fact that the anhydrite pills 363 are slightly watered during their elaboration. The field data obtained in anhydrite rocks also indicate 364 that the observed resistivity ranges fit better to the perpendicular or $\mathrm{HS}^{+}$models. The values obtained 365 for the pills with $60 \%$ in sulphate fraction are transitional, which represents the percolation threshold. 366 Theoretically the percolation threshold occurs in a single phase fraction but in the case of real rocks 367 transitional values are displayed in this range of composition.

From the trends observed for two-phase systems, it can be considered as approximation that 369 the HS bounds define the resistivity of gypsum and anhydrite rocks depending on the quantity of 
matrix present. When the matrix is percolating (sulphate fraction of $50 \%$ or below), the resistivity of

371 the sulphate rocks is bounded to the HS- model. In the case of non percolating matrix (sulphate 372 fraction of $70 \%$ or above), the resistivity is bounded to the $\mathrm{HS}^{+}$model. A general form of the bounds 373 for n-phases was given by Berriman (1995). With his formula it is possible to construct a ternary 374 graphic for 3-phased rocks (Ledo and Jones, 2005). The gypsum-Anhydrite-Lutite (GAL) system has 375 been calculated for both upper (Table 3G) and lower (Table 3H) HS bounds. In the case of lower 376 bound (Figure 7A), the system is clearly dominated by the lutitic component; the isoresistivity lines 377 are parallel between them showing no appreciable variation in the gypsum-anhydrite axis but when the 378 lutite fraction is less than $10 \%$. The values of resistivity are very low in general, showing less than 100 $379 \Omega . m$ for a sulphate fraction of $70 \%$. The upper bound (Figure $7 \mathrm{~B}$ ) displays a very different trend dominated by the anhydrite fraction, but in this case the 3 components affect the bulk resistivity value 381 of the rock. The electrical resistivity values are much larger than in the case of lower bound achieving $3821000 \Omega$.m with only $40 \%$ of anhydrite. As it has been previously shown, the electrical behavior of the 383 rocks is the one of lower HS bound when the quantity of sulphate is of $50 \%$ or below and the one of 384 upper bound when is of $70 \%$ or above. Thus it is expected that the real distribution of the electrical resistivity for the GAL system should be a combination between the upper and lower HS bounds 386 (Figure 7C).

\subsection{Results and discussion}

In order to check the accurateness of this GAL diagram, the theoretical electrical resistivity value of real thin section rock photographs (Figure 8) has been calculated with ELECFEM2D

390 program. Lutitic matrix display brownish coloring while both anhydrite and gypsum have are 391 transparent underplane polarized light; having anhydrite higher relief than gypsum (its bounds are well 392 marked with dark lines). With crossed polarized light, gypsum and anhydrite can be easily 393 differentiated because of the different coloring of the anhydrite (pink, green, blue, ...) in contrast with 394 the gray colors of the gypsum crystals. The standard electrical resistivity values selected for the gypsum, anhydrite and lutitic matrix phases have been $10^{3}, 10^{4}$ and $10 \Omega$.m respectively, as has been assigned before. The electrical resistivity of the bulk sections has been measured in both $x$ and $y$ 
directions; when the distribution of the components is homogeneous these values would be considered

398 similar. For each thin section the fractions of the components are calculated by the program so it is 399 possible to obtain the electrical resistivity value corresponding to these fractions calculated with different mixing models (Table 4).

The results show that the mean of the calculated electrical resistivity values in $x$ and $y$ directions are in general close to $\mathrm{HS}^{+}$bound when the fraction of sulphate is $70 \%$ or higher (Figure 8 , 403 thin sections A, D, E, F, G and H; Table 4) and to the $\mathrm{HS}^{-}$bound when the fraction of matrix is 404 abundant (Figure 8, B and I; Table 4). There is a good match between the corresponding position of 405 each sample in the figure 7C, according to their components percentages, and the calculated resistivity values. In the case of thin sections $\mathrm{C}$ and $\mathrm{J}$ there is abundant matrix (58 and 52\% respectively); nevertheless, the calculated resistivity values are slightly larger than that expected for such mixture. This is due to that the phases are not scattered and randomly distributed within the samples but 409 forming compact and pure areas. This represents large heterogeneities which change the percolating 410 behavior (we have considered it only for regular distributions of the phases as in the case of the pills) 411 of the bulk rock and makes the transition zone larger. In any case the values are always much closer to 412 the lower bound that to the upper one. The parallel/Modified Archie's law and perpendicular (serie) 413 models does not fit well to the calculated resistivities. The random model fits well in many cases but 414 in samples with large fraction of anhydrite, calculated resistivity is too high (especially in $\mathrm{C}$ thin 415 section).

At larger scale (as in the ERT profiles) the rocks are in general more homogeneous and should 417 fit to the HS lower bound for compositions of 0-60\% in lutitic matrix. The microscopic anisotropies do 418 not affect to the electrical conductivity of the bulk deposit if we increase the scale. In any case, it is 419 possible to observe cases of heterogeneities at metric scale. When these heterogeneities are large, they 420 can be considered as different rocks (for example a gypsum-rich lutite body within a larger pure 421 gypsum host-rock). In any case, heterogeneities below the detection limit of the method will be 422 considered as a single rock. Another possible case is a layered deposit in which every layer has 423 different purity in the sulphate phase. If the difference among grades is low, which is the most 
common case, the whole sequence can be considered as a single member with a mean grade. Rarely

sulphate deposits have great variations of grade from layer to layer forming a heterogeneous sequence.

Sudden variations in the grade exist, but are normally associated with the limit of a sequence or a stable change in the depositional conditions. In the case of having layering between almost pure matrix and highly pure sulphates, the transitional values of resistivity will increase their range as happens in the case of the microphotographs.

\section{GEOELECTRICAL CLASSIFICATION OF CALCIUM SULPHATE ROCKS}

With the GAL diagram obtained combining both $\mathrm{HS}^{+}$and $\mathrm{HS}^{-}$boundaries for a gypsum anhydrite-lutite system (Figure 7C) a geoelectrical classification has been elaborated differentiating 6 calcium sulphate rock types (Figure 9). When the lutitic matrix is connected at long range (in the case of sulphate fraction of $50 \%$ or below) the system is matrix dominant and therefore there is no possibility of differentiating between gypsum and anhydrite components; these rocks are classified as Lutites and Gypsum/Anhydrite rich Lutites. The electrical resistivity of this groups range from 10 to $100 \Omega . \mathrm{m}$. When the sulphate grade is of $70 \%$ or above, the rock will be considered as pure Gypsum when it ranges from 700 to $1000 \Omega . m$ as was stated by Guinea et al. (2010b) for the case of gypsumlutite systems. If the sulphate mineral is mainly anhydrite (more than 90\%) the rock is considered pure Anhydrite and its electrical resistivity value range from 2500 to $10^{4} \Omega . \mathrm{m}$ depending on the rock grade. In the case of presence of both gypsum and anhydrite sulphate phases, the rock is considered Gypsum

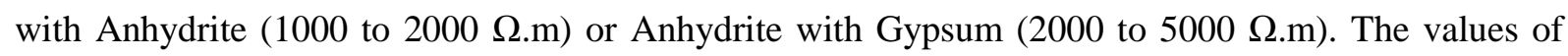
444 pure Anhydrite and Anhydrite with Gypsum overlap; in this case it is possible to bond the electrical 445 value to Pure Anhydrite rocks when there is no evidence of rehydration and to the Anhydrite with 446 Gypsum otherwise. Between Lutites and Gypsum/Anhydrite rich Lutites and the sulphate pure rocks 447 there is a transitional area displaying transitional values from 100 to $700 / 2500 \Omega$.m (depending of the 448 sulphate composition). The lower boundary of Transitional Gypsum/Anhydrite rocks has been selected as $55 \%$ in sulphate fraction instead of $60 \%$ because the measures in pills have shown that the $60 \%$ 
values display an electrical resistivity increasing trend; the upper boundary is $70 \%$ in gypsum fraction. This transitional area is displayed with a resistivity-trend calculated by interpolation between lower and upper HS bounds, but the resistivity in the transition zone is uncertain and therefore the displayed trend is only a reference.

For the microscopic scale, it has been shown that the transitional range is wider (including rocks between 55 and $70 \%$ in sulphate fraction, depending of the anisotropy). For the cases of sulphate fractions of $55 \%$ or below or higher than $70 \%$, the values obtained are similar to the corresponding HS bound. At larger scale, the ERT lines have shown relationships between composition and resistivity values similar to the ones displayed in the classification of the Figure 9; that is, higher than $5000 \Omega . m$ when the dominant phase is the anhydrite, 1500 to $5000 \Omega$.m for different proportions of gypsum and anhydrite (with presence of little lutite) and close to $1000 \Omega$.m when the gypsum is the dominant phase. For deposits with large amount of lutites, the obtained value has been $<60 \Omega$.m in all cases.

\section{CONCLUSIONS}

The electrical properties of calcium sulphate rocks have been widely studied at different scales with microphotographs, synthetic pills and geological deposits. Laboratory tests in pills have shown that the matrix of calcium sulphate rocks may be affected by the percolation phenomena and therefore, when the sulphate fraction in a rock is of $55 \%$ or below, the matrix controls the resistivity of the bulk rock. When the sulphate fraction is of $70 \%$ or above, the sulphate minerals control the electrical resistivity of the bulk rock.

The electrical resistivity value of anhydrite rocks range from 10 to $10^{4} \Omega . \mathrm{m}$, being larger in the purest anhydrite rocks. This value is found in the field examples where the anhydrite appears in massive form. The values observed in rocks with both gypsum and anhydrite (with minor matrix) have ranged between 1500 and $5000 \Omega$.m depending on the quantity of each other. Large quantity of matrix 
474 in sulphate rocks have shown low electrical resistivity values been unable to differentiate between 475 gypsum and anhydrite.

476

477

480

When the matrix of the calcium sulphate rocks is above the percolation threshold (i.e., more than $45 \%$ ), the electrical resistivity value fits the value calculated with the Hashin-Shtrikman lower bound ( $\mathrm{HS}^{-}$), and when is embedded in the sulphate phase (i.e., $30 \%$ of matrix or less) the resistivity follows the Hashin-Shtrikman upper bound $\left(\mathrm{HS}^{+}\right)$. If there are large heterogeneities in the distribution of the phases, the resistivities of rocks with a matrix quantity ranging from 30 to $45 \%$ can display transitional values (more than $100 \Omega . \mathrm{m}$, without reaching values of the purest sulphate rocks). Therefore, it is possible to calculate any combination of these 3 components and the geoelectrical classification has been elaborated for calcium sulphate rocks. With this classification is possible to determine the purity of the sulphates and the presence of anhydrite in gypsum rocks, which is useful for the characterization of the deposit.

\section{ACKNOLEDGEMENTS}

The present work is a part of a $\mathrm{PhD}$ thesis supported by the "Programa General d'Intensificació de la Recerca" (Generalitat de Catalunya-UB) and the Spanish Government Projects CGL2009-11096, CGL2009-07025, CGL2010-18260 and CGL2009-07604. We want to appreciate the support and facilities of Drs. Albert Casas, Esperança Tauler and Manel Labrador (Universitat de Barcelona, UB) and Dr. Ricard Bosch (Universitat Politècnica de Barcelona, UPC). We also want to thank to Grupo Uralita Corporation, especially to Ms. Mayte Martín, for letting us work in the quarry of Beuda and their support. 

Teshreen Structure in Northeast Syria. Exploration and Mining Geology, 11, 49-59.

499

500

501

502

503

504

Archie, G.E., 1942. The electrical resistivity $\log$ as an aid in determining some reservoir characteristics. Transactions of the American Institute of Mining, Metallurgical, and Petroleum Engineers, 146, 54-62.

Ayora, C., García-Veigas, J., Pueyo, J.J., 1994. The chemical and hydrological evolution of an ancient potash-forming evaporite basin as constrained by mineral sequence, fluid inclusion composition and numerical simulation. Geochimica et Cosmochimica Acta, 58, 3379-3394.

Berriman, J.G., 1995. Mixture theories for rock properties. In: T.J. Ares Ed., Rock Physics and Phase Relations: A Handbook of Physical Constants. American Geophysical Union, Washington, 236pp.

Bustillo, M., Calvo, J.P., Fueyo, L., 2001. Rocas Industriales: Tipología, aplicaciones en la construcción y empresas del sector. Rocas y Minerales (ed.). 410pp.

Carrillo, E., 2009. Unidades evaporíticas eocenas de la Zona Surpirenaica Oriental (Área de La Garrotxa). Geogaceta, 47, 73-76.

Chouteau, M., Phillips, G., Prugger, A., 1997. Mapping and monitoring softrock mining. In: Proceedings of Exploration 97: Fourth Decennial International Conference of Mineral Exploration, A.G. Gubins Ed., 927-940.

Deucester, J.\& Kaufmann, O., 2009. Correlation between inverted chargeabilities and organic compounds concentrations in soils-A field experiment. 15th Near Surface meeting, Dublin, Ireland, Expanded Abstracts, C19.

Furman, A., Ferré, P.A., Warrik, A.W., 2003. A Sensitivity Analysis of Electrical Resistivity Tomography Array Types Using Analytical Element Modeling. Vadose Zone Journal, 2, 416-423. 
Garboczi, E.J., 1999. Finite element and finite difference programs for computing the linear 521 electric and elastic properties of digital images of random materials. NIST Internal Report 6269. Also available at http://ciks.cbt.nist.gov/garbocz/

Giao, P.H., Chung, S.G., Kym, D.Y., Tanaka, H., 2003. Electric imaging and laboratory resistivity testing for geotechnical investigation of Pusan clay deposits. Journal of Applied Geophysics, 52, 157-175.

Glover, P.W.J., Gomez, J.B., Meredith, P.G., Boon, S.A., Sammonds, P.R., Murrell, S.A.F., 1996. Modelling the Stress/Strain Behaviour of Saturated Rocks Undergoing Triaxial Deformation using Complex Electrical Conductivity Measurements, In Integrated Experimental Measurements and Theoretical Modelling of Rock Transport Properties. Surveys in Geophysics, 17, 307-330. phases. Earth and Planetary Science Letters, 180, 369-383. rock physical properties. Tectonophysics, 279, 23-35. University Press, Princenton, NJ, 294pp. 
543 Gypsum Rocks. Surveys in Geophysics, 31 (6), 557-580. multiphase materials. Journal of the Mechanics and Physics of Solids, 11, 12-140. Sedimentary Petrology, 40, 734-744.

Geochemical methods in alabaster provenance: an application example. IX ASMOSIA:

550 Interdisciplinary Studies on Ancient Stone meeting, Tarragona, Spain, Abstracts 125. percolation theory. Physica A, 318, 113-120. of physical constants. The Geological Society of America, 587pp.

559 composition, electrical conductivity laboratory studies and magnetotelluric field observations:

560 Application to the intermontane belt, Northern Canadian Cordillera. Earth and Planetary Science $561 \quad$ Letters, 236, 258-268. 

an ERT system. Chemical Engineering Science, 52, 2197-2203. 540pp. sociedad geológica de España, 13, 227-249. evaporites of Spain: distribution and paleogeographic significance. Geological Quarterly, 54 (4), 411 422.

Rosell, L., Pueyo, J.J., 1997. Second marine evaporitic phase in the South Pyrenean Foredeep:

582 Schreiber, Ch. Eds. Sedimentary deposition in rift and foreland basins in France and Spain. Columbia 
586 Near Surface Geophysics, 8, 173-180.

Prensas Universitarias de Zaragoza, 72pp.

Shankland, T.J., Waff, H.S., 1977. Partial melting and electrical conductivity anomalies in the upper mantle. Journal of Geophysical Research, 82, 5409-5417. anhydrite. In: Schreiber, B.C., (Ed.), Sixth International Symposium on Salt, vol. 1, Salt Institute, 4155. systems. Elsevier, Amsterdam, 257pp.

$597 \quad 181 \mathrm{pp}$.

601 contact method of nonpolarizable electrodes on a base rock and detection of clay minerals by 602 normalised chargeability. Geophysical Exploration, 59, 363-370. 
608 Engineers Journal, 1, 153-169.

609 Warren, J.K., 2006. Evaporites: sediments, resources and hydrocarbons. Springer, 1035pp.

610 
612 Table 1: Geoelectrical classification of gypsum rocks (modified after Guinea et al. 2010b).

613 Table 2: Electrical resistivity values for anhydrite rocks in the literature.

614 Table 3: Summary of the equations of the mixing models used in the present study (modified from 615 Glover et al. 2000).

616 Table 4: Results of the theoretical calculations of electrical resistivity of the thin section photographs 617 with ELECFEM2D software. Parallel, Serie, Random, Archie's modified law and Lower (HS ${ }^{-}$) and 618 upper $\left(\mathrm{HS}^{+}\right)$Hashin-Shtrikman bounds have been calculated, only considering the proportion of each 619 phase. The calculated resistivity for each sample in both $x^{-}$and $y^{-}$directions is listed in the right 620 column. The corresponding images of the thin sections A to $\mathrm{J}$ are displayed in Figure 8.

\section{FIGURE CAPTIONS}

623 Figure 1: Photographs of the areas studied with ERT, A to C are taken in the Beuda quarry while D is 624 taken in the area of Odena and $\mathrm{E}$ in the Zaragoza formation. A) pure gypsum-anhydrite boundary with 625 a interdigitation between them; B) sulphate layers showing less gypsum fraction than in other areas; 626 C) anhydrite blocks filled with gypsum veins and embedded in a gypsum matrix; D) massive anhydrite 627 body; E) impure sulphate layers in Montes de Torrero area.

Figure 2: Distribution of evaporite formations in the Tertiary basins northeastern Spain indicating the location of the nine studied ERT profiles with black dots (modified from Ortí et al., 2010).

Figure 3: Inverted electrical resistivity tomography data for the different areas studied (the locations of the profiles are shown in figure 2). Profile F modified from Guinea et al. (2010b).

632 Figure 4: Electrical circuit to measure the electrical resistivity of the samples. It consists of a 633 switchable laboratory power-supply (EA-PS 3032-10B), two electrodes, a voltimeter (MY-67) and a 
634 micro or nanoammeter depending on the samples (Demestres, mod. 540; and Monroe, mod. 285 635 respectively).

636 Figure 5: Semi-logarithmic plots representing the results of the measurements of gypsum-lutite (A) 637 and anhydrite-lutite (B) pills. The symbols represent the mean of the calculated resistivities for each 638 sulphate fraction (using 2 pills and 3 different measurements on both for each fraction) and the error 639 bar represents the standard deviation. The error on the $\mathrm{X}$ axis is not showed because is below $1 \%$.

640 Figure 6: Different mixing models calculated for the case of gypsum-lutite (A) and anhydrite-lutite 641 rocks (B). The resistivity ranges obtained in the laboratory essays (Figure 5) are superimposed for both 642 cases.

643 Figure 7: Ternary plots showing Hashin-Shtrikman bounds for gypsum-anhydrite-lutite (GAL) 644 system. A) lower HS bound; B) upper HS bound; C) combined diagram considering the percolation 645 phenomena.

646 Figure 8: Microphotographs of thin sections of calcium sulphate rocks; D, E, H and I are taken with 647 cross polarized light and the rest with plane polarized light. The different phases are indicated with 648 numbers 1 (gypsum), 2 (anhydrite) and 3 (lutite/carbonate).

649 Figure 9: Geoelectrical classification of calcium sulphate rocks, depending on their gypsum650 anhydrite-lutite fraction. The resistivity values are shown in the background (Figure 7C).

651

652

653

654

655

656

657 658

\section{ANNEX}

Annex 1: Results of the laboratory measurements on synthetic pills made by mixing powdered pure anhydrite or gypsum with clay. G samples correspond to gypsum-lutite pills, while A samples correspond to anhydrite-lutite pills. Samples with a sulphate fraction of $70 \%$ or above have been measured with a nanoammeter and the rest with a microammeter. The mean resistivity for each fraction and the standard deviation is showed in Figure 5. 


\begin{tabular}{|l|c|c|}
\hline & Purity in Gypsum (\%) & Resistivity (ohm.m) \\
\hline $\begin{array}{l}\text { Lutites and Gypsum } \\
\text { rich Lutites }\end{array}$ & $0-55$ & $10-100$ \\
\hline $\begin{array}{l}\text { Transitional } \\
\text { Gypsum }\end{array}$ & $55-75$ & $100-700$ \\
\hline Pure Gypsum & $75-100$ & $700-1000$ \\
\hline
\end{tabular}




\begin{tabular}{|l|c|l|}
\hline REFERENCE & $\begin{array}{c}\text { RESISTIVITY } \\
(\mathrm{ohm} . \mathrm{m})\end{array}$ & AUTHOR'S COMMENTS \\
\hline Lugo et al. (2008) & $1000-11500$ & $\begin{array}{l}\text { The bodies displaying the lowest values are related to the presence of } \\
\text { gypsum from the hydration of anhydrite while the highest ones are related to } \\
\text { pure anhydrite. }\end{array}$ \\
\hline $\begin{array}{l}\text { Asfahani and } \\
\text { Mohammad (2002) }\end{array}$ & $94-1200$ & $\begin{array}{l}\text { The values are measured by vertical electrical soundings in a gypsum } \\
\text { and anhydrite formation. }\end{array}$ \\
\hline $\begin{array}{l}\text { Choteau et al. } \\
\text { (1997) }\end{array}$ & 1000 & Anhydrite appears in an halite-karnalite-tachyhydrite sequence. \\
\hline $\begin{array}{l}\text { Robinson and } \\
\text { Çoruh (1988) }\end{array}$ & $10^{9}-10^{10}$ & Anhydrite appears in a summary of different mineral resistivity values \\
\hline Rider (1986) & $10^{4}-10^{10}$ & Obtained from wireline logs of different sources. \\
\hline Parkhomenko (1967) & $1.0-10^{9}$ & Listed in a summary of different mineral and rock resistivities \\
\hline Jakosky (1950) & $1.00^{3} / 1.0-10^{5}$ & Low and High resistivity ranges obtained from laboratory measurements \\
\hline
\end{tabular}




\begin{tabular}{|c|c|c|c|}
\hline & Name & Conducting phases & Equation \\
\hline a) & Parallel model & $1+$ & $\sigma_{\mathrm{eft}}=$ \\
\hline b) & Perpendicular model & $1+$ & $\frac{1}{\sigma_{\text {eff }}}=\sum_{i=1}^{N} \frac{\chi_{i}}{\sigma_{i}}$ \\
\hline c) & Random model & $1+$ & $\sigma_{\mathrm{eff}} \prod_{i}^{N} \sigma_{i}^{\chi_{i}}$ \\
\hline d) & Modified Archie's law & $1-2$ & $\sigma_{\mathrm{eff}}=\sigma_{1}\left(1-\chi_{2}\right)^{p}+\sigma_{2} \chi_{2}^{m}$ where $p=\frac{\log \left(1-\chi_{2}^{m}\right)}{\log \left(1-\chi_{2}\right)}$ \\
\hline e) & $\begin{array}{l}\text { Hashin-Shtrikman upper } \\
\text { bound }\end{array}$ & 2 & $\sigma_{\mathrm{eff}+}=\sigma_{2}\left(1-\frac{3\left(1-\chi_{2}\right)\left(\sigma_{2}-\sigma_{1}\right)}{3 \sigma_{2}-\chi_{2}\left(\sigma_{2}-\sigma_{1}\right)}\right)$ \\
\hline f) & $\begin{array}{l}\text { Hashin-Shtrikman lower } \\
\text { bound }\end{array}$ & 2 & $\sigma_{\mathrm{eff}-}=\sigma_{1}\left(1+\frac{3 \chi_{2}\left(\sigma_{2}-\sigma_{1}\right)}{3 \sigma_{1}+\left(1-\chi_{2}\right)\left(\sigma_{2}-\sigma_{1}\right)}\right)$ \\
\hline g) & $\begin{array}{l}\text { Hashin-Shtrikman upper } \\
\text { bound }\end{array}$ & 3 & $\sigma_{\mathrm{eff}+}=\frac{1}{\left(\frac{\chi_{1}}{\sigma_{1}+2 \sigma_{2}}\right)+\left(\frac{\chi_{2}}{3 \sigma_{2}}\right)+\left(\frac{\chi_{3}}{\sigma_{3}+2 \sigma_{2}}\right)}-\sigma_{2}$ \\
\hline h) & $\begin{array}{l}\text { Hashin-Shtrikman lower } \\
\text { bound }\end{array}$ & 3 & $\sigma_{\mathrm{efI}-}=\frac{1}{\left(\frac{\chi_{1}}{\sigma_{1}+2 \sigma_{3}}\right)+\left(\frac{\chi_{2}}{\sigma_{2}+2 \sigma_{3}}\right)+\left(\frac{\chi_{3}}{3 \sigma_{3}}\right)}-2 \sigma_{3}$ \\
\hline
\end{tabular}




\begin{tabular}{|c|ccc|cccccc|cc|}
\cline { 2 - 12 } \multicolumn{1}{c|}{} & \multicolumn{9}{c|}{ COMPOSITION (\%) } & \multicolumn{5}{c|}{ MIXING MODEL $(\Omega . m)$} & \multicolumn{2}{c|}{ CALCULATED $(\Omega . m)$} \\
\hline Thin section & Gy & Anh & Lut & Parallel & Series & Random & HS. & HS+ & X & Y \\
\hline A & 95 & 0 & 5 & 168 & 951 & 794 & 365 & 928 & 862 & 844 \\
B & 17 & 0 & 83 & 12 & 178 & 22 & 16 & 129 & 16 & 16 \\
C & 0 & 42 & 58 & 17 & 4206 & 2630 & 32 & 1091 & 214 & 126 \\
D & 0 & 83 & 17 & 59 & 8302 & 3090 & 154 & 4504 & 3087 & 3157 \\
E & 29 & 71 & 0 & 2770 & 7390 & 5129 & 4417 & 6684 & 5070 & 6024 \\
F & 68 & 32 & 0 & 1404 & 3880 & 2089 & 1947 & 3230 & 1622 & 2265 \\
G & 26 & 51 & 23 & 43 & 5361 & 1122 & 105 & 2105 & 1102 & 2474 \\
H & 53 & 34 & 13 & 74 & 3931 & 1202 & 185 & 1708 & 1129 & 1940 \\
I & 35 & 6 & 59 & 17 & 956 & 76 & 30 & 408 & 33 & 82 \\
J & 38 & 10 & 52 & 19 & 1385 & 115 & 36 & 540 & 65 & 210 \\
\hline
\end{tabular}




\begin{tabular}{|c|c|c|c|c|c|c|c|c|c|c|c|}
\hline Sample & Sulphate fraction (\%) & Thickness (cm) & Voltage $1(\mathrm{mV})$ & Voltage $2(\mathrm{mV})$ & Voltage $3(\mathrm{mV})$ & Current $1(\mu \mathrm{A})$ & Current $2(\mu \mathrm{A})$ & Current $3(\mu \mathrm{A})$ & Resistivity 1 ( $\Omega . \mathrm{m})$ & Resistivity 2 ( $(\Omega . m)$ & Resistivity $3(\Omega . \mathrm{m})$ \\
\hline G1 & 0 & 0.49 & 12 & 11 & 13 & 90 & 90 & 95 & 5 & 4 & 5 \\
\hline G1' & 0 & 0.49 & 15 & 23 & 11 & 74 & 96 & 78 & 7 & 9 & 5 \\
\hline G2 & 10 & 0.49 & 22 & 14 & 12 & 70 & 64 & 28 & 11 & 8 & 15 \\
\hline $\mathrm{G}^{\prime}$ & 10 & 0.49 & 14 & 12 & 23 & 60 & 56 & 73 & 8 & 8 & 11 \\
\hline G3 & 20 & 0.50 & 11 & 15 & 14 & 28 & 35 & 37 & 13 & 15 & 13 \\
\hline G3' & 20 & 0.50 & 15 & 12 & 12 & 42 & 40 & 14 & 12 & 11 & 30 \\
\hline G4 & 30 & 0.49 & 16 & 31 & 21 & 28 & 48 & 74 & 20 & 23 & 10 \\
\hline G4' & 30 & 0.50 & 18 & 14 & 12 & 36 & 24 & 49 & 18 & 21 & 9 \\
\hline G5 & 40 & 0.52 & 33 & 30 & 35 & 37 & 37 & 78 & 30 & 28 & 16 \\
\hline G5' & 40 & 0.50 & 34 & 42 & 45 & 21 & 50 & 38 & 57 & 30 & 40 \\
\hline G6 & 50 & 0.51 & 41 & 19 & 36 & 20 & 23 & 39 & 71 & 29 & 32 \\
\hline G6' & 50 & 0.50 & 43 & 40 & 42 & 12 & 14 & 21 & 126 & 101 & 71 \\
\hline G7 & 60 & 0.52 & 26 & 30 & 29 & 10 & 12 & 8 & 88 & 85 & 123 \\
\hline G7' & 60 & 0.51 & 32 & 41 & 21 & 6 & 9 & 4 & 185 & 158 & 182 \\
\hline G8 & 70 & 0.51 & 3 & 2 & 3 & 0.120 & 0.096 & 0.144 & 866 & 722 & 722 \\
\hline G8' & 70 & 0.50 & 2 & 3 & 4 & 0.070 & 0.132 & 0.139 & 1009 & 803 & 1017 \\
\hline G9 & 80 & 0.52 & 3 & 3 & 2 & 0.092 & 0.067 & 0.095 & 1108 & 1522 & 715 \\
\hline G9' & 80 & 0.52 & 4 & 3 & 3 & 0.126 & 0.132 & 0.067 & 1078 & 772 & 1522 \\
\hline G10 & 90 & 0.51 & 3 & 2 & 1 & 0.070 & 0.050 & 0.036 & 1484 & 1386 & 962 \\
\hline G10' & 90 & 0.51 & 2 & 4 & 2 & 0.082 & 0.088 & 0.040 & 845 & 1575 & 1732 \\
\hline G11 & 100 & 0.52 & 1 & 1 & 1 & 0.013 & 0.016 & 0.012 & 2613 & 2124 & 2832 \\
\hline G11' & 100 & 0.53 & 2 & 1 & 1 & 0.040 & 0.022 & 0.030 & 1667 & 1515 & 1111 \\
\hline A1 & $\overline{0} 0$ & 0.49 & 16 & 15 & $\overline{14}$ & 97 & 93 & 94 & $\bar{~} 6$ & $\bar{~} 6$ & $\bar{~} 5$ \\
\hline$A 1^{\prime}$ & 0 & 0.48 & 13 & 17 & 11 & 89 & 92 & 88 & 5 & 7 & 5 \\
\hline$A 2$ & 10 & 0.49 & 15 & 18 & 19 & 55 & 60 & 57 & 10 & 11 & 12 \\
\hline$A 2^{\prime}$ & 10 & 0.50 & 18 & 22 & 12 & 62 & 67 & 67 & 10 & 12 & 6 \\
\hline A3 & 20 & 0.50 & 17 & 26 & 18 & 40 & 43 & 37 & 15 & 21 & 17 \\
\hline$A 3^{\prime}$ & 20 & 0.50 & 20 & 19 & 22 & 42 & 44 & 45 & 17 & 15 & 17 \\
\hline A4 & 30 & 0.50 & 18 & 22 & 25 & 33 & 40 & 35 & 20 & 20 & 26 \\
\hline$A 4^{\prime}$ & 30 & 0.51 & 23 & 24 & 32 & 26 & 28 & 26 & 31 & 30 & 43 \\
\hline A5 & 40 & 0.50 & 36 & 23 & 43 & 33 & 24 & 58 & 37 & 13 & 25 \\
\hline$A 5^{\prime}$ & 40 & 0.50 & 32 & 32 & 56 & 66 & 62 & 71 & 17 & 18 & 28 \\
\hline A6 & 50 & 0.52 & 29 & 44 & 44 & 41 & 42 & 50 & 25 & 36 & 30 \\
\hline$A 6^{\prime}$ & 50 & 0.50 & 35 & 37 & 50 & 32 & 33 & 30 & 39 & 40 & 59 \\
\hline A7 & 60 & 0.52 & 43 & 55 & 39 & 2 & 3 & 2 & 731 & 623 & 663 \\
\hline$A 7^{\prime}$ & 60 & 0.53 & 31 & 43 & 43 & 1 & 1 & 1 & 1074 & 1490 & 1490 \\
\hline A8 & 70 & 0.51 & 2 & 1 & 1 & 0.035 & 0.028 & 0.022 & 1980 & 1237 & 1575 \\
\hline$A 8^{\prime}$ & 70 & 0.52 & 1 & 2 & 2 & 0.023 & 0.026 & 0.033 & 1537 & 2718 & 2142 \\
\hline A9 & 80 & 0.53 & 2 & 1 & 2 & 0.021 & 0.013 & 0.021 & 3236 & 2614 & 3236 \\
\hline$A 9^{\prime}$ & 80 & 0.52 & 2 & 2 & 1 & 0.033 & 0.037 & 0.019 & 2059 & 1837 & 1788 \\
\hline A10 & 90 & 0.52 & 1 & 1 & 1 & 0.007 & 0.009 & 0.010 & 4950 & 3850 & 3465 \\
\hline A10' & 90 & 0.53 & 1 & 1 & 1 & 0.009 & 0.004 & 0.007 & 3850 & 8662 & 4950 \\
\hline A11 & 100 & 0.52 & 1 & 1 & 1 & 0.004 & 0.005 & 0.008 & 8495 & 6796 & 4248 \\
\hline $\mathrm{A} 11^{\prime}$ & 100 & 0.52 & 1 & 1 & 1 & 0.005 & 0.003 & 0.004 & 6668 & 11113 & 8335 \\
\hline
\end{tabular}



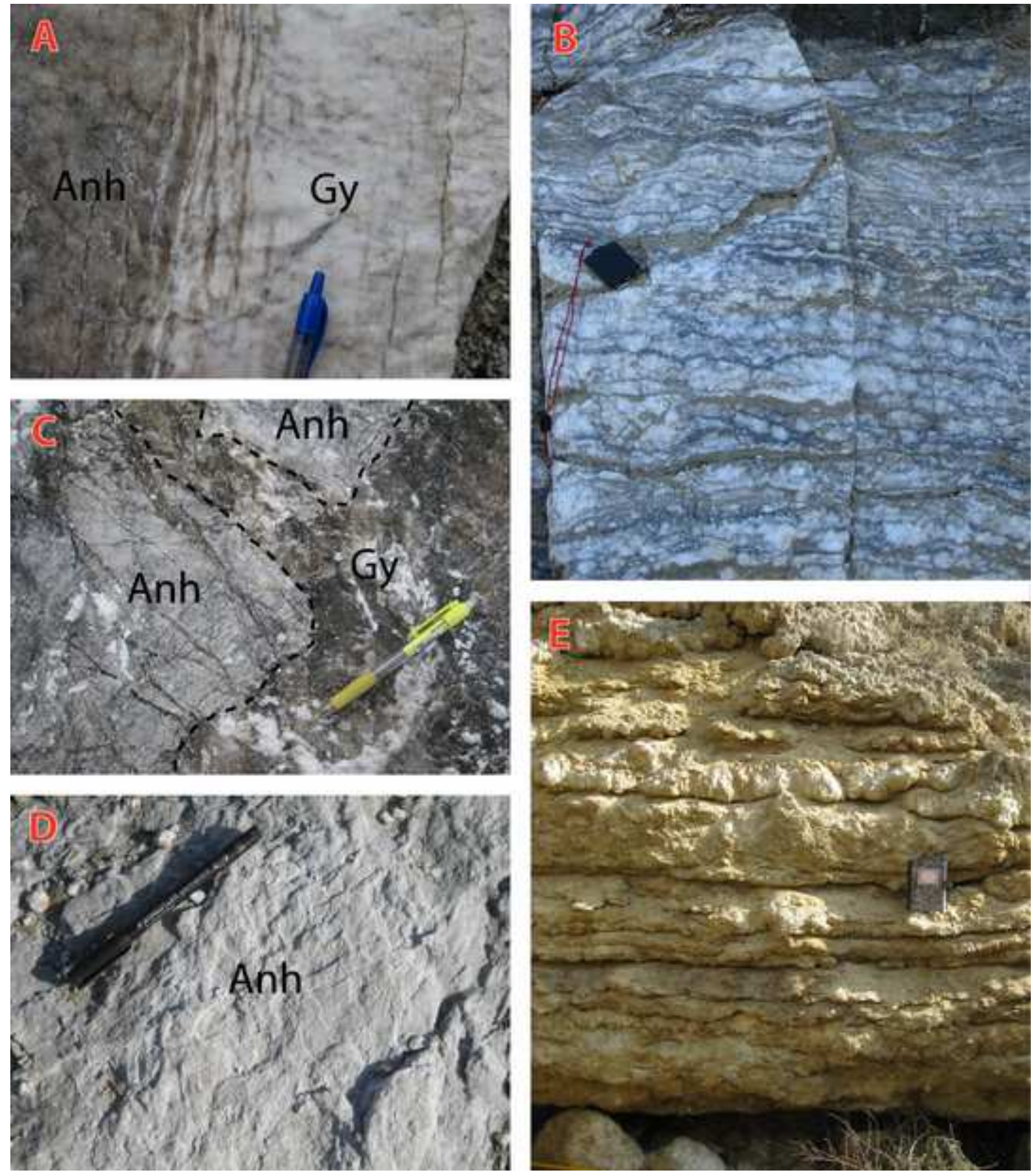

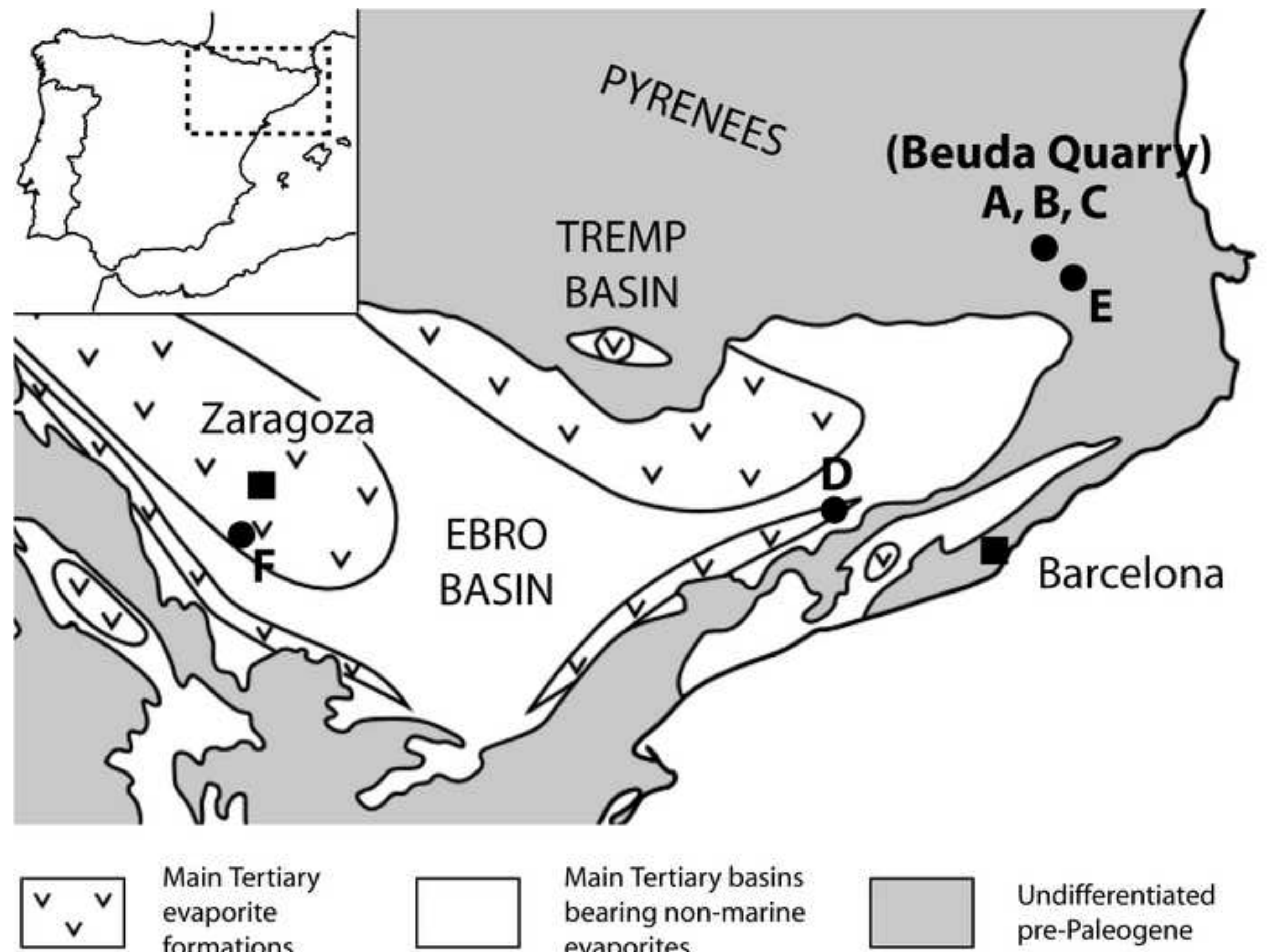

Main Tertiary evaporite formations
Main Tertiary basins bearing non-marine evaporites
Undifferentiated pre-Paleogene 
Figure 03

Click here to download high resolution image

A Degeh Hestions ausserrot - ins

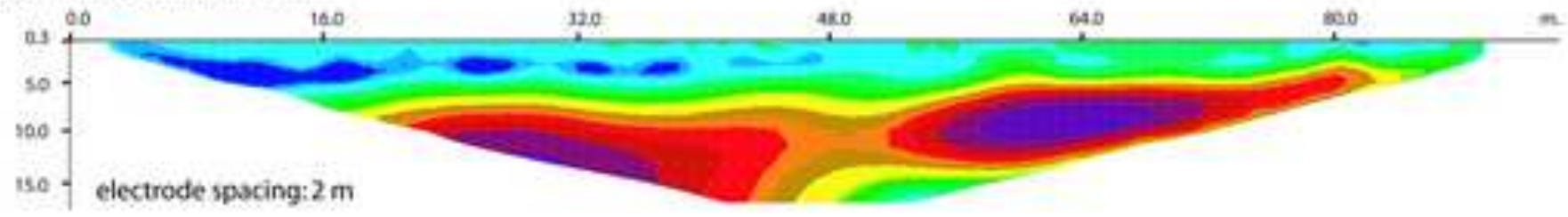

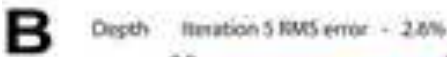

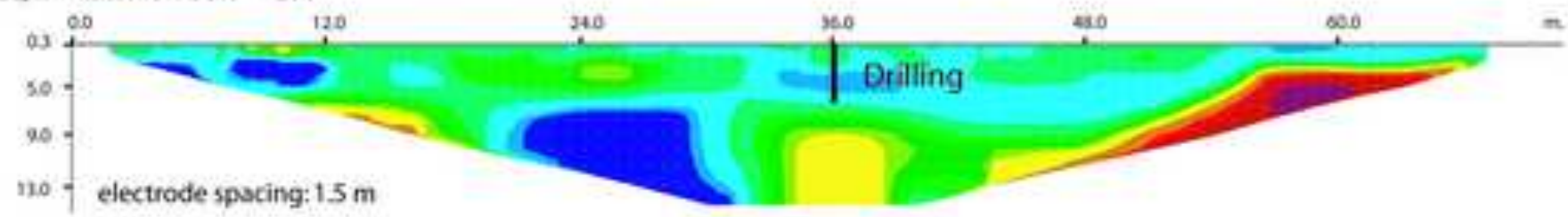

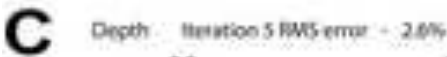

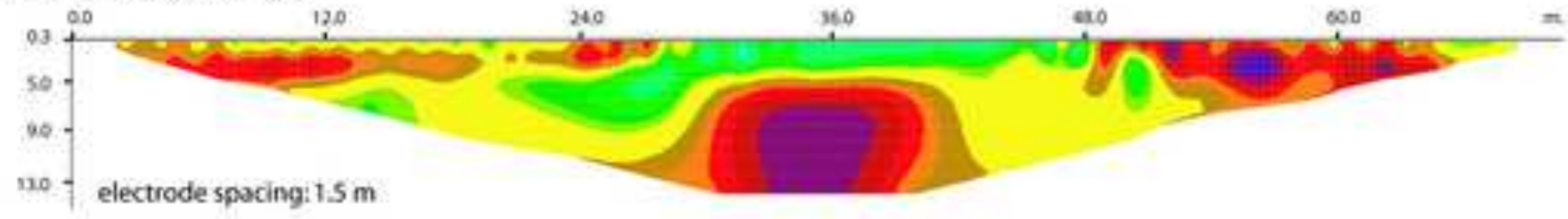

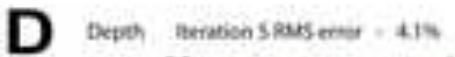

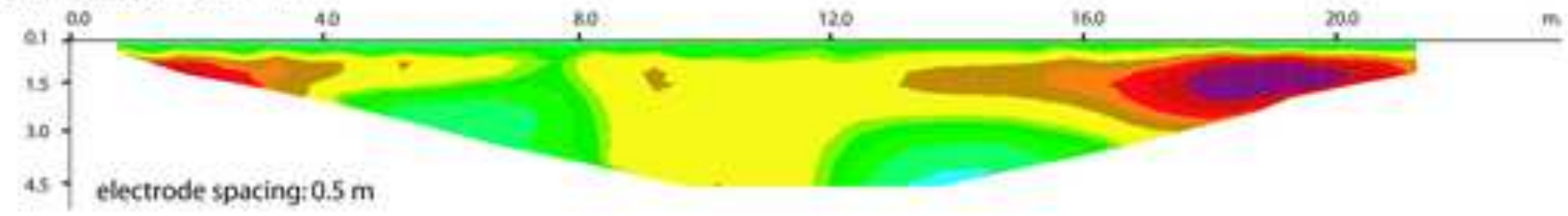

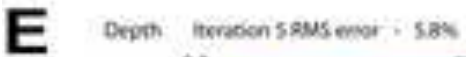

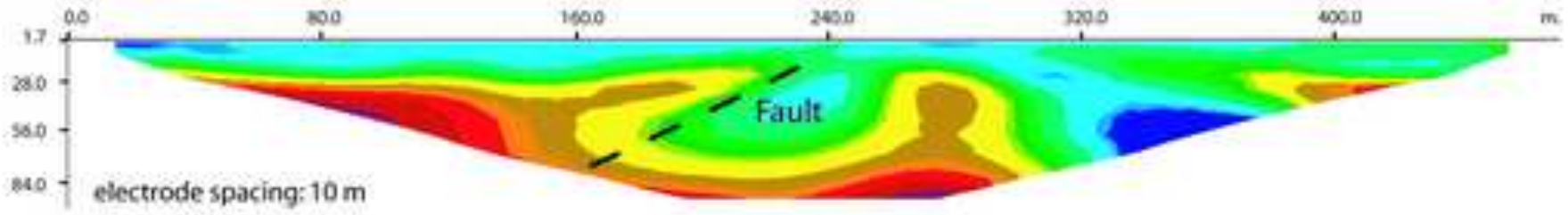

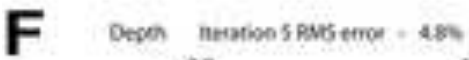
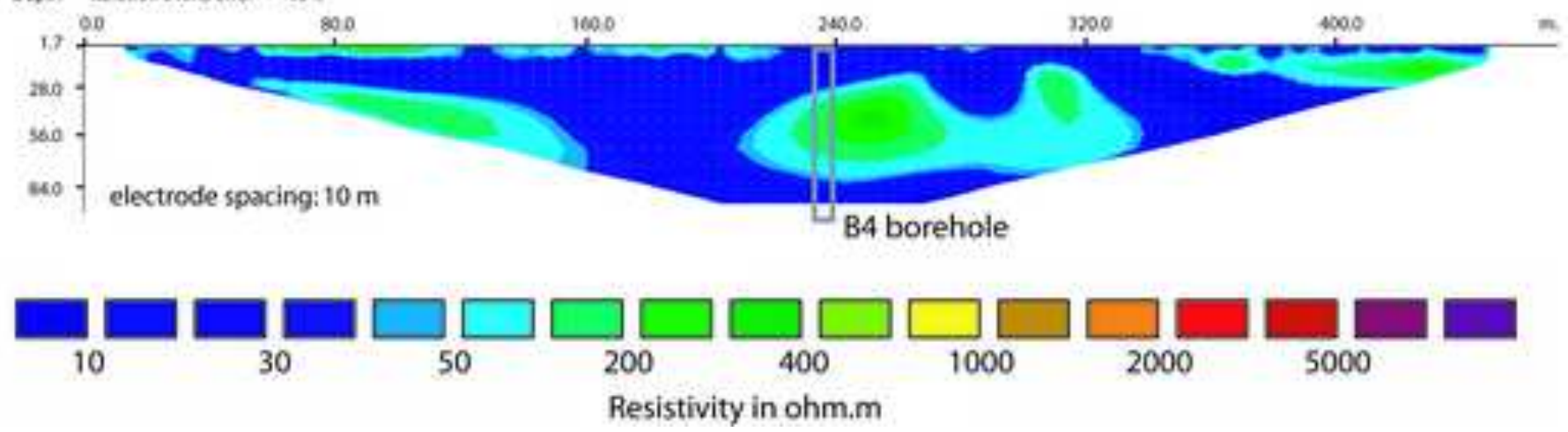
Click here to download high resolution image

\section{Current Supply}

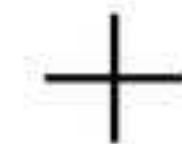

Voltmeter

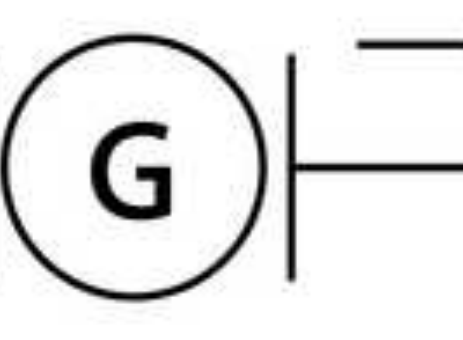

A

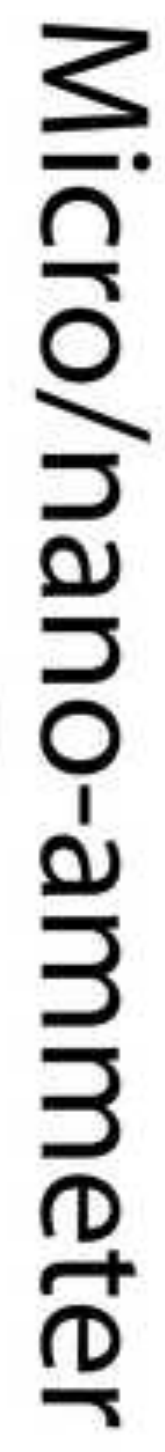

Pill 


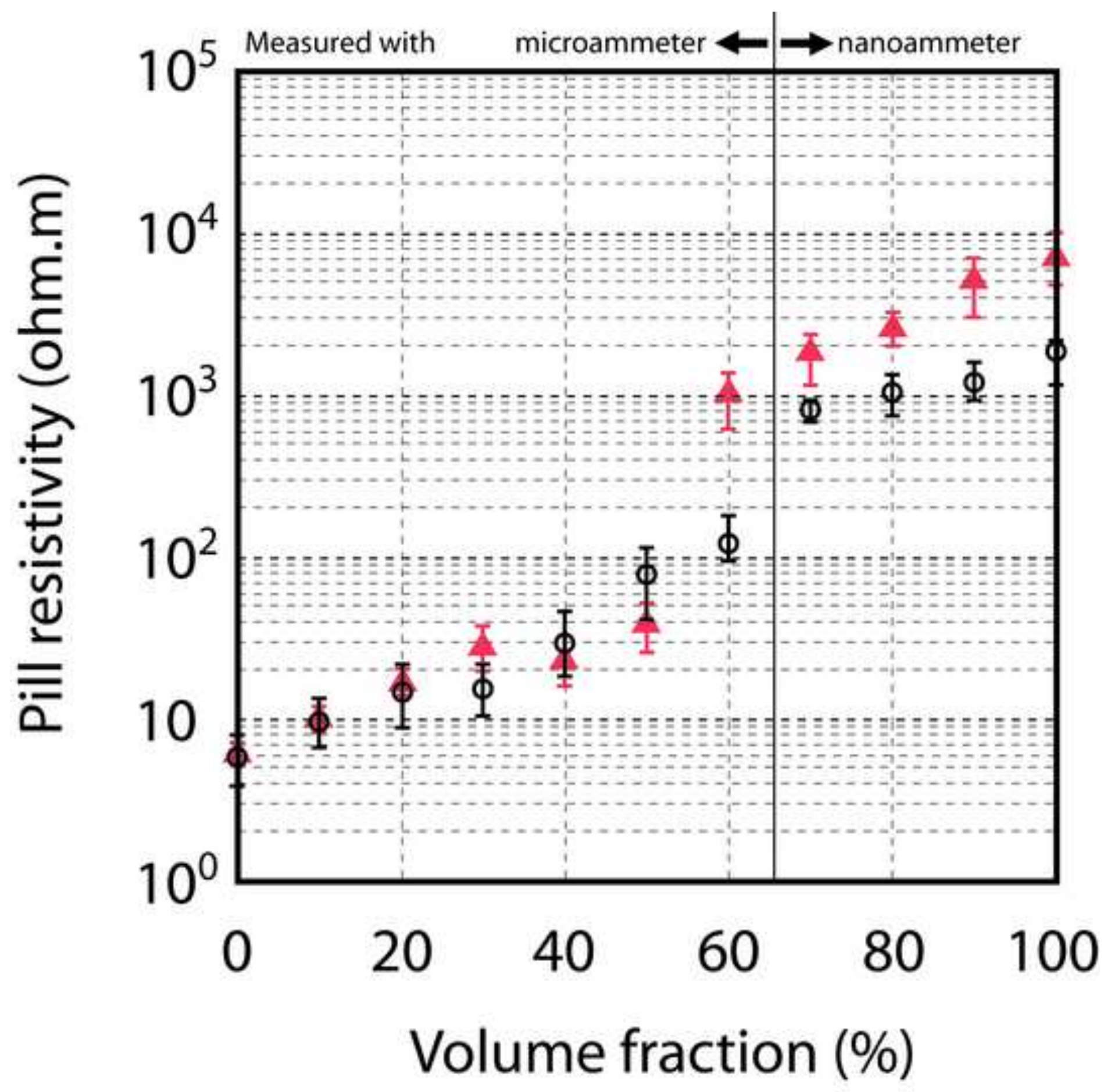

I Anhydrite pills

$\Phi$ Gypsum pills 
A GYPSUM vs LUTITE MATRIX

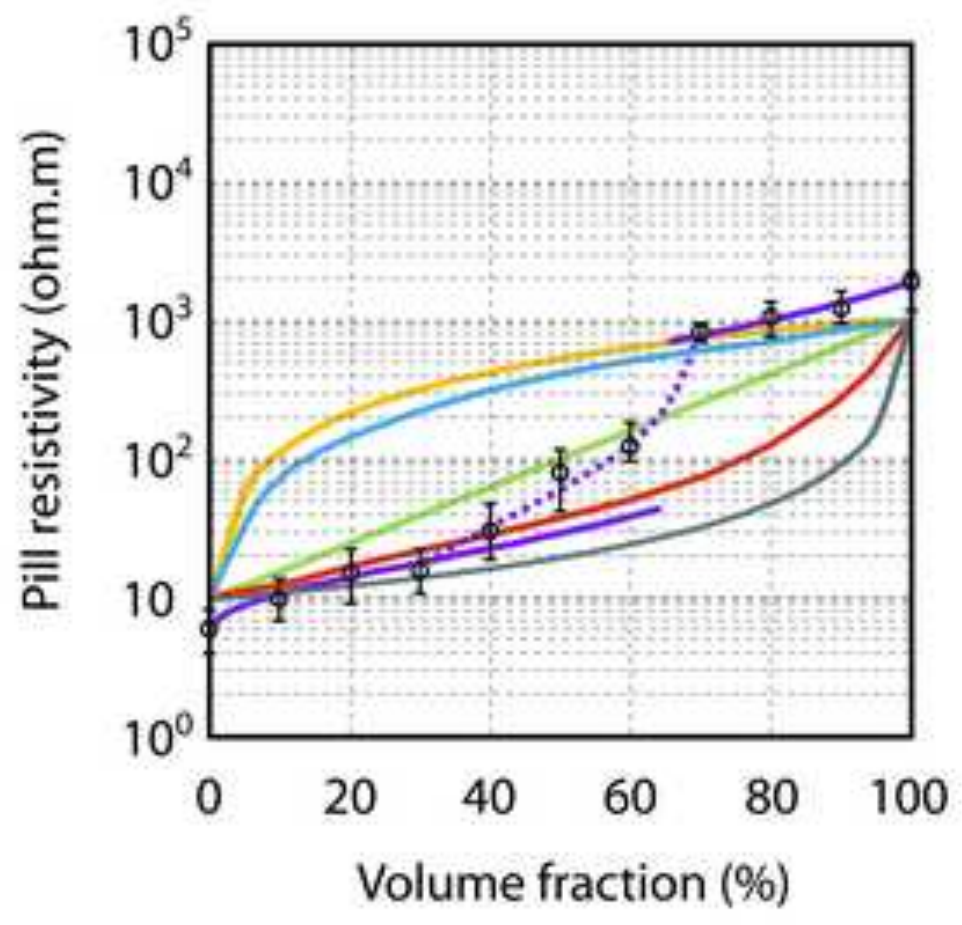

B ANHYDRITE vs LUTITE MATRIX

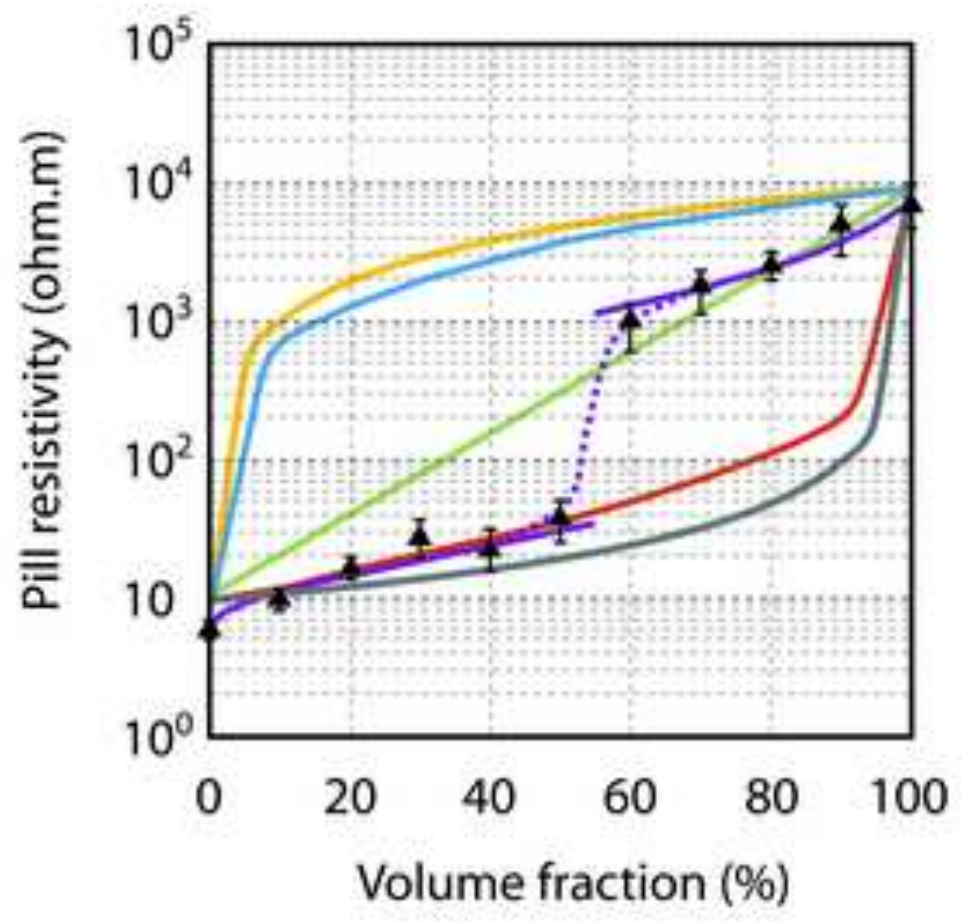

1 Anhydrite pills $\Phi$ Gypsum pills

$-\mathrm{HS}^{-} \quad-$ Parallel

- $\mathrm{HS}^{+}$- Serie

- Random - Modified Archie's law 
Click here to download high resolution image

A Gresum

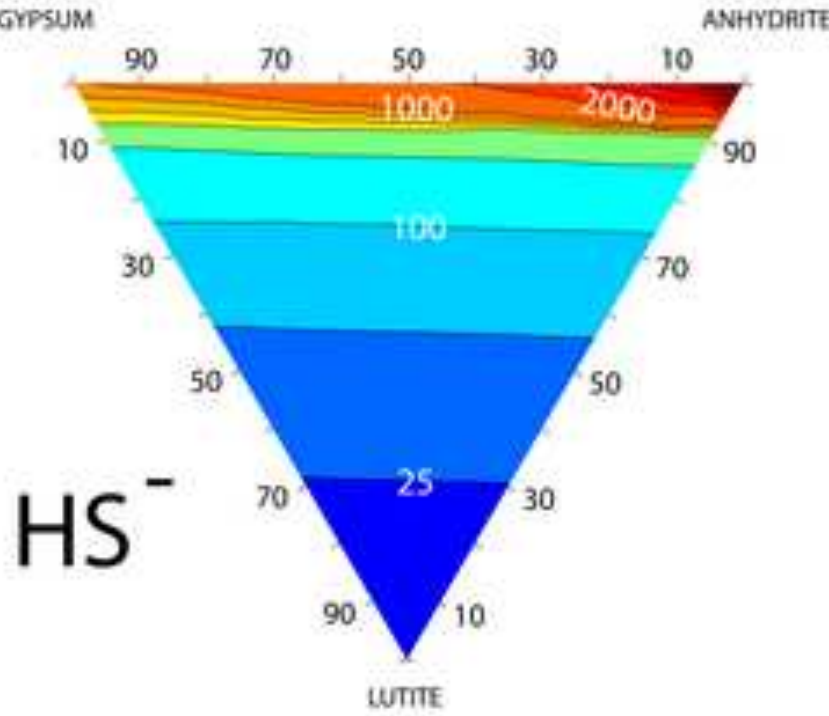

B

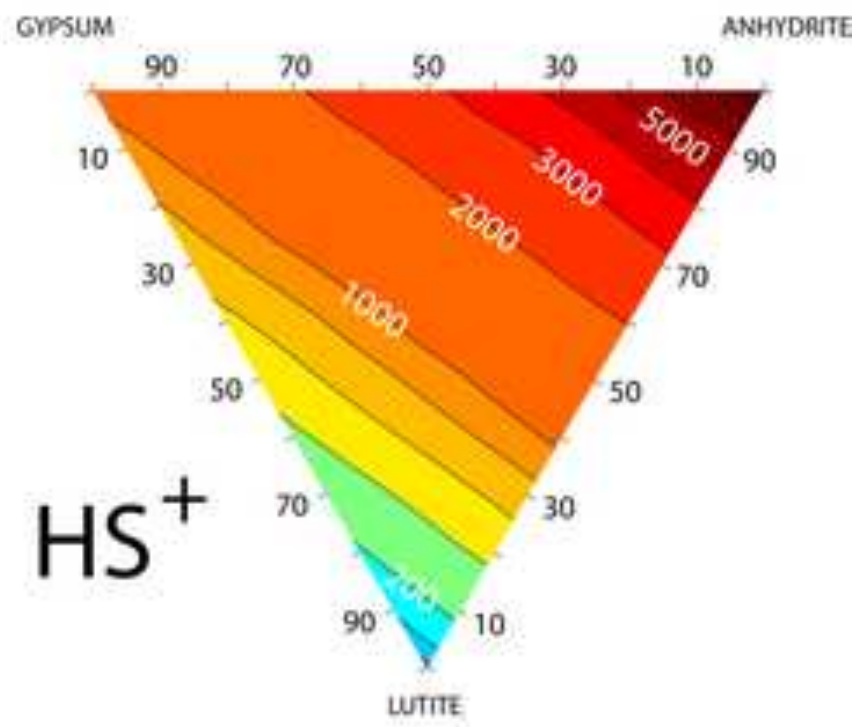

C

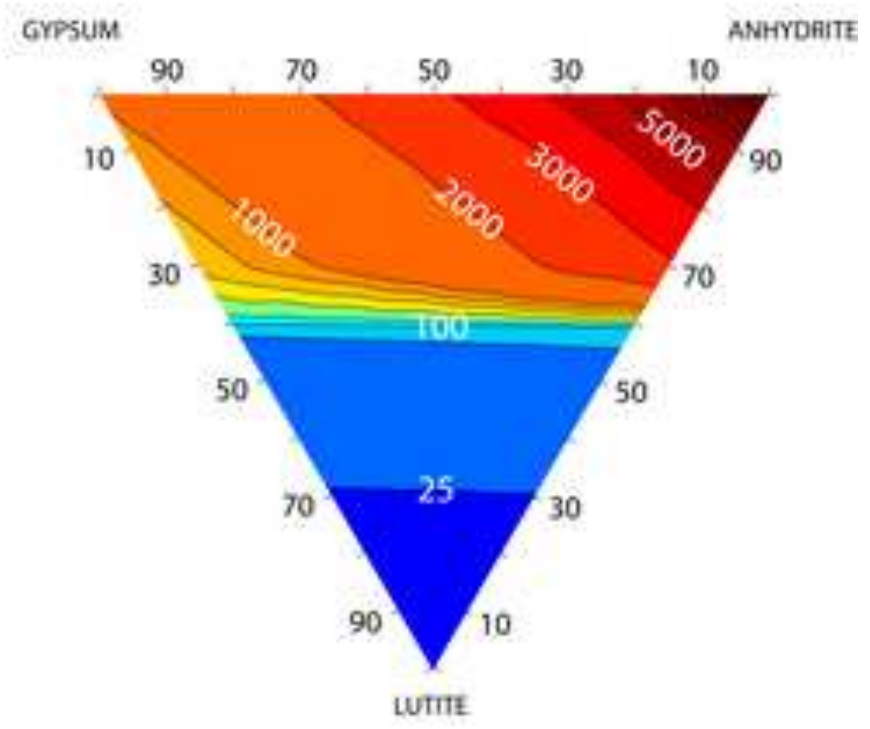

Resistivity (ohm.m)

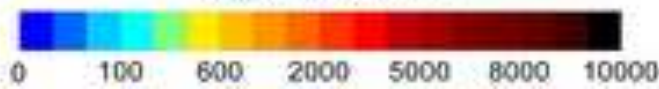



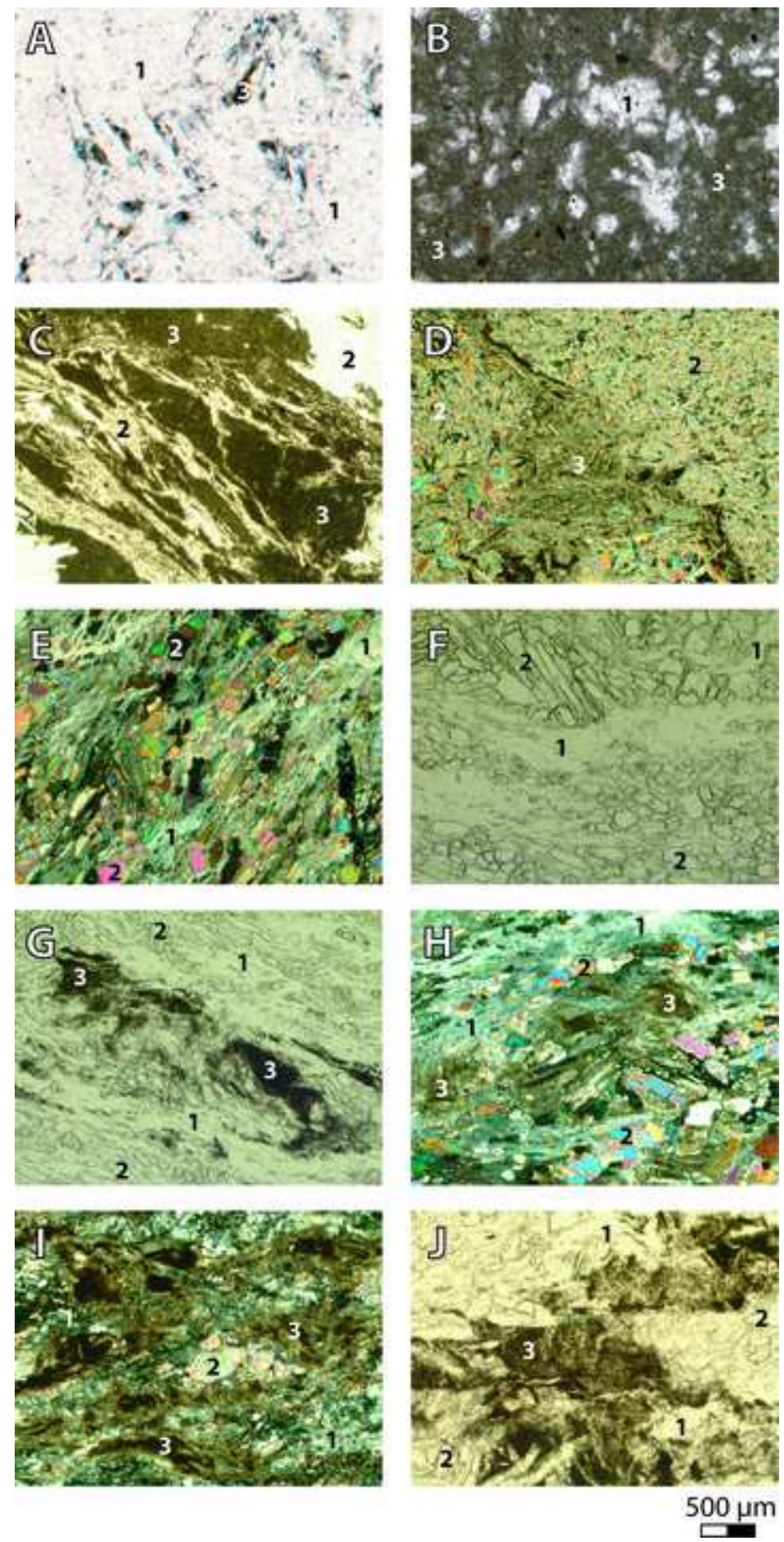


\section{GYPSUM}

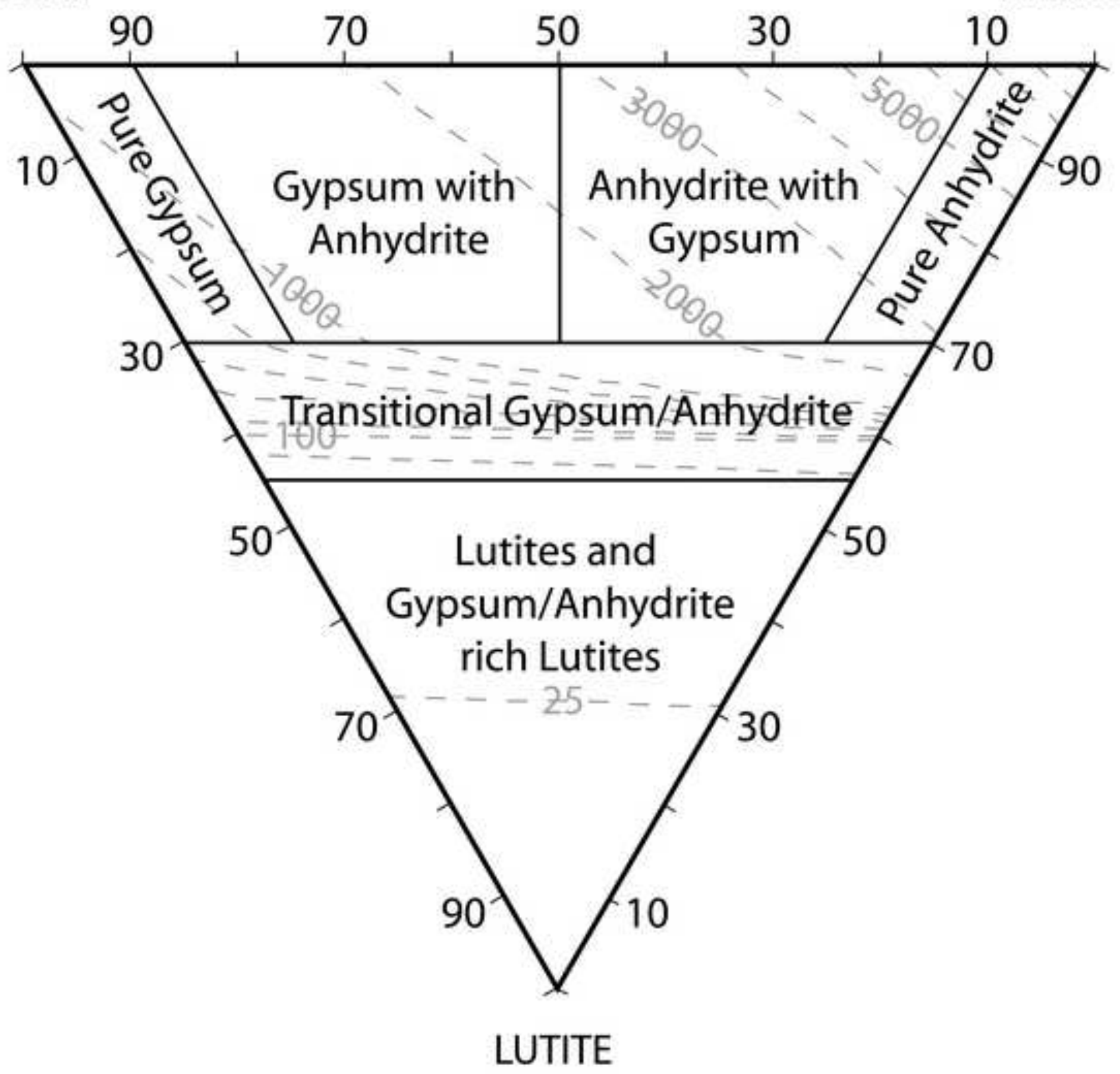

